\title{
Reflexiones acerca del "Concejo de la Puente": origen y desarrollo en los ss. XIII-XIV
}

\author{
Antonio Sáez Espligares * \\ Antonio M. Sáez Romero *
}

\begin{abstract}
RESUMEN
Este trabajo centra su atención en dos aspectos relacionados con la historia medieval del actual municipio gaditano de San Fernando: por un lado, la realización de una nueva revisión de los testimonios documentales y arqueológicos disponibles con objeto de reconstruir su desarroIlo histórico durante los ss. XIII-XV; por otro, el análisis de los efectos del ataque portugués a la Bahía de Cádiz en 1369, bisagra histórica que delimita dos horizontes, antes y después del suceso. Intentaremos mostrar una síntesis del poblamiento bajomedieval isleño, conjuntando por primera vez la información transmitida por los textos y el novedoso caudal de datos aportado por la arqueología urbana y las excavaciones realizadas en el Castillo de la Puente. Con ello tratamos de destacar algunos aspectos hasta ahora minusvalorados de uno de los términos más importantes de la bahía gaditana.
\end{abstract}

PALABRAS CLAVE: La Puente de Cádiz. Castillo de la Puente. 1369. Puente de Suazo. Rayhana. Caño de Sancti Petri.

\section{INTRODUCCIÓN}

El Lugar de La Puente de Cádiz es actualmente uno de los enclaves menos conocidos de la etapa medieval de la bahía gaditana, en espe-

\begin{abstract}
In this paper we will focus our attention on two important aspects related with the medieval evolution of the present city of San Fernando: in one hand a new review on the documental and archaeological evidence is made and, in the other hand, we analyze the effects of the portuguese strike of 1369. This action of war has turned now into an historical limit which defines two sides in the history of medieval city. We try to make a synthesis of the medieval population, putting togheter the information that comes from the written sources and the new facts arisen from urban archaeology as well as the excavations in the castle of La Puente de Cádiz. The main objective of this article is to give a new impulse to the research of this medieval village of the Cádiz Bay.
\end{abstract}

KEY WORDS: La Puente of Cádiz. Castle of La Puente. 1369. Suazo Bridge. Rayhana. Sancti Petri.

cial debido a la escasez de documentos disponibles, al desconocimiento arqueológico no subsanado hasta fechas muy recientes y a la falta de estudios monográficos al respecto, ya que salvo contadas y valiosas excepciones (CRIS-

* Museo Histórico Municipal de San Fernando. C/ Real, 63. I I 100 - San Fernando (Cádiz) 
TELLY, I89|; ZURITA, 1947; TORRES BALBÁS, 1950; CLAVIJO, 196I; FRANCO, 1995 y 1997), hasta el momento su mera existencia como entidad poblacional medieval ha pasado casi desapercibida para la mayor parte de la comunidad investigadora. Partiendo de esta situación y con estos condicionantes, planteamos este trabajo con el propósito principal de incentivar la investigación de esta parcela tan desconocida de la actual ciudad de San Fernando, heredera de La Puente, a través de un estado de la cuestión actualizado de las investigaciones acometidas sobre el que intentaremos acomodar las novedades que por fin la arqueología ha aportado en los últimos años.

En efecto, intentaremos realizar por vez primera un recorrido histórico-arqueológico a través de la secuencia de ocupación medieval del término isleño, conjugando la información de época islámica y la posterior a la reconquista y repoblación, como parte de un mismo proceso en el que pueden rastrearse cambios pero también pervivencias. Para ello, hemos reunido buena parte de las fuentes documentales referidas al territorio, fortaleza, puente y poblado isleños, dispersas en otros trabajos (CRISTELLY, 1891; CLAVIJO, 196I; ABELLÁN, 1996; FRANCO, 1995) a fin de generar un primer punto de referencia para la investigación. Asimismo, en el plano arqueológico, habremos de tomar como referencia principal las importantes novedades aportadas por las excavaciones que desde el verano de 2000 se efectúan en uno de los pilares de la fase medieval de la ciudad, el Castillo de La Puente (actualmente denominado de San Romualdo), sin perder de vista otros cauces informativos como la arqueología urbana o los hallazgos subacuáticos que también contribuyen a llenar los vacíos documentales. Las intervenciones en la fortaleza (SÁEZ, TORREMOCHA y SÁEZ, 2004 y e.p. a-b), además de contribuir decisivamente a su recuperación y rehabilitación (fig. I), prometen aportar a corto plazo páginas perdidas de este lapso histórico, habiendo dado ya frutos las investigaciones tanto para dicha etapa como para la ocupación del lugar en la Antigüedad (SÁEZ ET ALII, 2005 y e.p.). En estas páginas intentaremos conjugar la información de los textos y los restos arqueológicos, vertebrando a partir de ello un discurso histórico sobre el Logar de la Puente, incidiendo en cuestiones diversas -esbozadas por otros autores- relacionadas con su desarrollo diacrónico: su identificación con el solar de la actual San Fernando, los cambios en su alfoz, su papel socio-económico, las actividades económicas desarrolladas, la ubicación del poblado y la posible existencia de alquerías asociadas, etc...

\section{LOS PRECEDENTES: LA ISLA EN ÉPOCA ISLÁMICA}

Escasos son los datos literarios y arqueológicos con los que contamos para valorar la Qãdis islámica, su papel dentro de la cora de Saḍuna (ABELLÁN, 2004) y acerca de aspectos urbanísticos o de patrón de ocupación y explotación del territorio (una síntesis actualizada en CAVILLA, 2002). Sin embargo, la revisión de ambos tipos de fuentes y las aportaciones que las actividades arqueológicas efectuadas en la bahía van sumando al caudal informativo ya existente están permitiendo desarrollar en los últimos años una visión más ajustada de la bahía en época islámica y acerca del paso de dicho régimen socio-económico y administrativo al dominio cristiano hacia mediados del s. XIII. Dejaremos en esta ocasión los precedentes más remotos de la ciudad, que nada tienen que ver con los objetivos centrales de este trabajo, resaltando las últimas fases urbanas de Qãdis durante el dominio almorávide y sobre todo almohade, así como la articulación del territorio insular y campiña costera circundante en dicho momento. Se trata de una fase de clara reactivación de la ciudad como enclave portuario comercial-militar de importancia, así como de recuperación de la explotación agropecuaria de la isla gaditana y los términos continentales fronteros, incrementándose el número de alquerías y posiblemente activándose un programa integral de recuperación de estructuras viarias y puntos fuertes defensivos y relacionados con la yihād.

En este sentido, parece factible pensar que el recinto urbano del Cádiz musulmán de esta última etapa constituyese una especie de alhizām o al-'askar, una especie de campamen- 
to militar amurallado, que hace pensar en un ribāt-campamento permanente, al menos durante el periodo de dominación almorávide y almohade, cuando se impone la institución del ribāt en al-Andalus. Este ribāț-campamento estaría encargado de la vigilancia de la costa, convirtiéndose en refugio de los pobladores de la isla y punto de concentración de los guerreros para la guerra santa o yihād (PAVÓN, 1996: | 81-184; Ibid., 1999: 32), así como puerto destacado en las rutas comerciales en dirección a Sevilla y el Atlántico y base de flotas militares (ABELLÁN, 2002: 137). También siguiendo a B. Pavón, la defensa de la bahía gaditana desde el ribāt-campamento de Cádiz se complementaría con la presencia de torres atalayas y dos grandes fortalezas: el castillo de San Romualdo en San Fernando y el castillo de San Marcos en el Puerto de Santa María, que responden al tipo de fortaleza-ribāt autónoma con mezquita (PAVÓN, 1996: 185; Ibid., 1999: 138- |40). Estos dos enclaves secundarios, en conjunción con la importante rábita de Rota, estarían situados en puntos geoestratégicos clave para el control del territorio: junto a sendos puentes (sobre el Guadalete y el Caño de Sancti Petri) pertenecientes a la vía principal que unía Cádiz y Xerez, con facilidad para el aprovisionamiento de agua dulce, controlando un amplio espacio agrícola circundante que sin duda englobaba múltiples explotaciones rurales diseminadas por los actuales términos de El Puerto de Santa María, Puerto Real, Chiclana y San Fernando. Recientemente, J. Abellán ha puntualizado esta tesis acerca de estos dos puntos fuertes secundarios, insistiendo quizá en el carácter de ribāț del actual Castillo de San Marcos e incluyendo al Castillo de San Romualdo como un posible al-munastir (ABELLÁN, 2002: I34-I35), si bien compartiendo en líneas generales los mismos planteamientos.

Desde estas bases, y conjugando la información aportada por los textos y la evidencia arqueológica, intentaremos acercarnos al poblamiento desarrollado en el área que posteriormente integraría el Logar de la Puente, analizando la articulación del territorio y aspectos esenciales como la toponimia a fin de entender el proceso de paso de estas realidades económicas y administrativas al dominio alfonsí. Algunos testimonios escritos medievales que corresponden a informaciones transmitidas por algunos autores islámicos' aportan algunos indicios sobre la entidad y carácter de la ocupación previa a la reconquista castellana del solar de

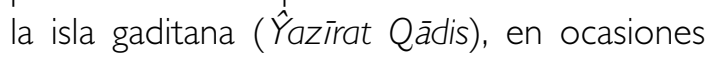
relacionados con el derrotero de rutas comerciales ya en funcionamiento al menos durante los ss. XII-XIII. Destacan en primer lugar un par de textos que refieren la travesía entre Algeciras y Sevilla:

"De Algeciras a Sevilla hay dos caminos: uno por mar y otro por tierra. El primero es éste: De Algeciras a los bancos de arena que se encuentran en el mary de allí a la desembocadura del río Barbate, 28 millas. De allí a la desembocadura del río Beca, 6 millas. Desde allí al estrecho de San Pedro, 12 millas. Desde allí a los Puentes, frente a frente de la isla de Cádiz, 12 millas (...)" (AL-IDRISII, Geografia de España, pp. 166167).

"De Algeciras a Tarifa; a al-Rimāl; al río Barbate hay veintiocho millas, al río Bakka hay diez millas, a la bahía (halq) de San Pedro hay doce millas, a Santa María del Puerto (al-Qanātir), frente a la isla de Cádiz, hay doce millas, de la isla (...)" (AL-IDRISIT, Los caminos de al-Andalus..., p. 83).

En estos textos, Al-Idrīī nos informa claramente cómo la ruta entre estas dos importantes ciudades de Al-Andalus comprendía la navegación interior a través del caño para completar el tramo entre la desembocadura del mismo en Sancti Petri (Sant Bātar) y probablemente el enclave religioso-fortificado situado en la desembocadura del Guadalete en El Puerto de Santa María (al-Qanātir). Reflejo de la existencia de esta ruta bien podrían ser los pecios de los ss. XI-XII documentados en la entrada meridional del caño hace algunos años

I Los textos de autores árabes han sido tomados en su totalidad de la obra de J. Abellán Pérez (1996). 
(GALLARDO y MARTÍ, 1998; GALLARDO ET ALII, 1995 y 1998; CAVILLA, 2002a-b y 2003), fruto probablemente de la existencia de un lugar de fondeadero en las inmediaciones. Estas evidencias indican la frecuentación marítima del caño y su posición como un área diferenciada de la propia Cádiz y de la desembocadura del Guadalete, dejando entrever quizá su uniformidad administrativa-geográfica.

Asimismo, otros testimonios nos acercan al tipo de poblamiento desarrollado y a la toponimia del entorno de la bahía, al margen de señalar los puntos clave de su ocupación, con Cádiz como área urbana principal y la existencia de diversos enclaves fortificados y agrícolas girando entorno a ella:

"Al Sur de Sevilla se encuentra Cádiz (Qādis) a orillas del Océano. Al este de Cádiz se halla el gran río, llamado Guadalete (Wādī Lakka) cuya agua se utiliza para beber y para lavar. Según cuentan los cristianos en sus crónicas, existía sobre él un puente de treinta arcos. Dicho río desemboca en el Océano a través de una boca llamada Sancti Petri (Sant Bātar) (...)" (ALZUHRI, El mundo en el siglo XII, pp. I57|6I).

"La isla de Cádiz se halla en la desembocadura del río de Sevilla y mide doce millas de largo; toda ella es un arenal llano y el agua potable se extrae de pozos. Contiene restos de templos antiguos y dos castillos, uno llamado Sancti Petri y el otro al-Mal'ab (el teatro). En Sancti Petri hay una iglesia muy venerada por los cristianos (...)" (Una descripción anónima..., II, pp. 7I-73).

"Península de Al-Andalus, a alguna distancia de Itálica, una de las ciudades de la región de SeviIla. La longitud de esta península, de Sur a Norte, es de doce millas; y su máxima anchura, una milla. Está cubierta de cultivos de rica vegetación. Los rebaños son en su mayor parte de cabras. En la parte boscosa de la península, crecen pinos e inhiesta. (...) Se ve todavía sobre la cima que se encuentra al otro lado de la península, las ruinas de un antiguo castillo. En ese mismo lugar se eleva la iglesia conocida bajo el nombre de San Pedro. (...) En la misma península hay numerosos restos que datan de la anti- güedad. De estos restos, el más sorprendente es el templo, ordinariamente designado con el nombre de esta península. (...) El templo de Cádiz estaba situado en el centro de la península, a una distancia de seis millas del castillo de que se habló antes (...)" (AL-HIMYART̄: Kitāb al-rawḍ al-mi'țār fi habar al-aqtāir, pp. 290-298).

“(...) una isla separada en el océano (Atlántico), en cuyo mar, del lado del continente, se encuentran las ruinas de un acueducto por el que pasaba el agua dulce desde tierra firme en tiempos de los cristianos. Cuenta asimismo con viñedos y huertos por los que los cristianos del Norte han campeado, incendiándolos" (IBN SA'ĪD ALMAGRIBĪ: Kitāb al-Mugrib fĩ ḥulà al-Magrib, II, 309).

Estas informaciones resultan de capital importancia para definir el poblamiento desarrollado en el resto del territorio de la isla de Cádiz, destacando algunas referencias toponímicas que ayudan a clarificar la estructuración de dicha ocupación. Por un lado, los textos destacan la existencia de importantes restos urbanos de época antigua correspondientes a la ciudad de Gades, que fueron en buena medida reaprovechados por la urbe islámica: entre ellos sobresalen el templo o ídolo y el acueducto altoimperial que traía agua dulce desde el Tempul hasta la isla cruzando gran parte de ella. Por otro, los testimonios escritos permiten vislumbrar como, al margen del carácter del núcleo urbano situado bajo la capital actual, la isla y su entorno estarían ocupadas por un hábitat rural disperso, dedicado fundamentalmente a la pesca, la ganadería y la agricultura, actividades que mencionan continuamente las fuentes árabes al referirse a la cora de Saḍuna. Así, si bien el Dikr indica que toda la isla es un arenal Ilano (Dikr II, 7|-73), Ibn Sa'īd nos habla de viñedos y huertos (Ibn Sa'īd, II, 309), y al-Himyarī de cultivos de rica vegetación (alHimyarī, 290-298), mientras que todos ellos relatan la abundancia de pozos de agua dulce. Este último destaca asimismo la presencia de rebaños de cabras y otros tipos en menor medida, lo que señala una cierta diversificación de las actividades. Además, podemos suponer un aprovechamiento de las áreas boscosas del este de la isla según informa al-Himyarī, en 
relación al resto de actividades rurales llevadas a cabo en alquerías diseminadas por el solar insular. Lo referido en los textos denota con claridad la existencia de un aprovechamiento agropecuario especialmente en la etapa almohade del área extra-urbana de la isla gaditana coincidente especialmente con el actual término municipal de San Fernando (fig. 2), conocida desde la Antigüedad por su fertilidad (Str. III, 5, 3), proceso similar al que debía acontecer paralelamente en el contorno continental de la bahía. Esta proliferación de alquerías en la última etapa islámica de la ciudad parece confirmarla la documentación en la zona central del término isleño de dos áreas de silos agrícolas y fosas domésticas en los yacimientos de Sector III Camposoto (CAVILLA, 2003 y e.p.) y Campo del Gayro (fig. 3), pertenecientes probablemente a una de estas explotaciones, así como otros puntos como el yacimiento chiclanero de La Mesa (RAMOS ET ALII, 1998; FERNÁNDEZ, GARCÍA y SÁNCHEZ, 2003) y la alquería almohade documentada en el yacimiento portuense del Castillo de Doña Blanca (RUIZ y PÉREZ, 1995: 50).

Pero por encima de estos datos, los textos manifiestan la existencia de un castillo situado en la actual capital (el titulado "el teatro", identificado con el castillo de la villa cimentado sobre el teatro romano de Gades) y de otro contrapuesto a este situado en Sancti Petri, junto al cual se ubicaba una afamada iglesia dedicada a dicha advocación. Por una parte, la explícita mención a la existencia de una fortaleza en el actual término isleño bien podría corresponder a dos posibles realidades: la existencia ya por esas fechas del actual Castillo de San Romualdo o la situación de otro bastión fortificado en la desembocadura meridional del caño de Sancti Petri. La inexistencia de evidencias documentales y arqueológicas en el primero parecen decantar la cuestión hacia el segundo punto, donde es posible pudiera edificarse alguna construcción defensiva quizá en el islote que alberga el castillo artillero de época moderna o en la cercana Punta del Boquerón, quizá una torre de atalaya edificada tras las frecuentaciones normandas. Sin embargo, no es descartable que la monumentalidad de los restos del templo de Melqart-Hércules Gaditano, confundiese a los navegantes y cronistas árabes al referirse a este lugar como antigua fortaleza. Algunos autores como J. A. Fierro Cubiella opina que el topónimo San Pedro se encuentra muy extendido por toda la actual Isla de León y podría ser la denominación primitiva del Castillo de San Romualdo (FIERRO, 1991: 28-29). Para Fierro, esta fortaleza sería construida al igual que el "castillo del teatro", edificado según el Dikr en la ciudad de Cádiz, en el siglo IX y por iniciativa del emir 'Abd al-Raḥmān || (FIERRO, 1991: 42-43 y 5 I) como parte del entramado defensivo costero contra las incursiones normandas. La iglesia de San Pedro (Sant Bātar) situada junto a este castillo plantea sin embargo incertidumbres más profundas. Es posible que este lugar de culto, mantenido durante el dominio islámico en virtud de la tolerancia religiosa previa a los almorávides-almohades (ABELLÁN, 2002: 126-128), se corresponda con la consolidación del centro de culto denominado Nono fundado por San Fructuoso en la isla gaditana en el s. VII (CONCEPCIÓN, 1690, libro IV; CLAVIJO, 196I: 90-97; ABELLÁN, 2002: 127). La ubicación aislada del antiguo templo pagano en el extremo meridional de la isla, permitiría el reaprovechamiento de sus estructuras para la edificación de un núcleo conventual que permitiera la perpetuación de la actividad religiosa cristiana hasta comienzos del s. XII. La creencia en la predicación en el entorno del apóstol o la identificación de su figura con el Hércules pagano quizá justifiquen esta advocación, posiblemente generada ya en la etapa final del templo en la Antigüedad Tardía. El topónimo no sólo fosilizó con gran éxito como denominación del islote, sino que también se extendió a todo el caño marino que desemboca junto a él.

Por último, y en relación con la toponimia administrativa, cabe destacar la mención de la localización "los Puentes" (al-Qanātir), que se correspondería según la mayor parte de autores con el actual Puerto de Santa María de origen alfonsino (ABELLÁN, 1996; GONZÁLEZ JIMÉNEZ, 1982; 1983; 1999; 2002). En este punto, es necesario reconsiderar el papel del posible castillo o al-munastir situado en el emplazamiento del actual Castillo de San Romualdo isleño y su papel como cabeza de un término 
que desde la reconquista castellana pasa a denominarse como «concejo de la Puente» en base a su proximidad e interrelación con el inmemorial Puente de Suazo. Sobre el Castillo de la Puente, algunos investigadores si no la mayoría defiende que sería una obra del siglo XIV inicial (siguiendo la senda marcada por L. Torres Balbás), pero levantada por alarifes musulmanes, que, siguiendo sus tradiciones constructivas, copiarían el modelo de un ribāt islámico (TORRES, 1950: 213). Sin embargo, esta datación bien en los reinados de Alfonso $X o$ Alfonso $X I$ no es compartida por autores como Basilio Pavón, quien afirma que ciertas características arquitectónicas presentes en la fortaleza que Torres Balbás consideraba que no podían fecharse con anterioridad al siglo XIII, ya aparecen en edificaciones del siglo XII. Mantiene que el Castillo de la Puente (actualmente de San Romualdo) sería originariamente un ribāt-convento, posiblemente de época almohade, reutilizado y reformado en el reinado de Alfonso XI (PAVÓN, 1999: 138), complemento de las restantes fortificaciones de la bahía sitas en Rota, Puerto de Santa María y la propia Cádiz. Las excavaciones acometidas en las campañas de 2000-2003 en el citado castillo isleño han permitido definir con cierta claridad algunos eventos vividos por la fortaleza en época castellana, si bien por el momento no han aportado argumentos decisivos en la referente a su construcción que en base a la evidencia material es difícil retrotraer más allá de un momento avanzado del reinado del Rey Sabio (SÁEZ, TORREMOCHA y SÁEZ, 2004 y e.p. a-b; SÁEZ, e.p.), aunque existen evidencias significativas correspondientes a la presencia romana y tardorromana en el lugar (SÁEZ ET ALII, 2005 y e.p.). Recientes e interesantes interpretaciones de J. Abellán Pérez centran su origen en la existencia en el lugar de un al-munas- tir, aunque es probable que se asentara sobre estructuras anteriores de época romana (ABELLÁN, 2002: 134-135) y defiende la existencia de una fortaleza musulmana, que sería conocida como «La Puente» (Al-Qanțara) por su proximidad al paso elevado para el acueducto que se dirigía a la ciudad de Gades, y que debió constituirse en el centro de un distrito administrativo que englobaba varias alquerías (ABELLÁN, 2004: 75 y en prensa). Siguiendo la tesis expuesta por Abellán, creemos que se debieran revisar algunos conceptos relacionados con la cuestión: por un lado, la extensión del término de la etapa almohade denominado al-Qanātir al área ocupada por los puentes que le daban nombre, el de Zuazo y el arruinado existente sobre el Guadalete a la altura del El Puerto de Santa María. La referencia del topónimo islámico a "los Puentes"'2 en plural parece apuntar en su concepción como conjunto quizá parte de un mismo distrito administrativo articulado entorno a las fortalezas (de carácter religioso) ubicadas en sus extremos -San Marcos y San Romualdocabeza de un significativo número de alquerías encargadas de la explotación de un vasto territorio insular y continental. Quizá este aspecto pueda haber quedado reflejado en la transición de este "distrito" al dominio alfonsí, momento en el cual se rebautiza la fortaleza portuense como Santa María del Puerto y se delimita un amplio término denominado "de la Puente" (vid. disposiciones reales de 126870 infra) que comprende el territorio insular de San Fernando y las áreas continentales de Chiclana y parte de Puerto Real con sus alquerías correspondientes. Este término, según consta en documentos de 1335 (vid. infra) lindaba al este y norte con "Medina Sidonia, (...) é con las aguas dulces", es decir, ¿con el Guadalete o el San Pedro?

\footnotetext{
2 Abellán (2004: 75) señala respecto a esta cuestión: "Otro punto conflictivo es el del nombre que llevaba este distrito administrativo. Desde los primeros diplomas cristianos del siglo XIII, cuya cronología se sitúa en los primeros momentos en que fue aplastada la sublevación mudéjar, se le llama La Puente de Cádiz, denominación que revela una substrato árabe femenino, al-qantara (La Puente). El segundo término de este binomio no responde, a mi entender, a una dependencia de tipo administrativo, sino más bien de tipo geográfico, es decir, al hecho de que allí existiera un puente que facilitaba el acceso a la Isla de Cádiz, vinculando estrechamente ambas poblaciones". Este autor asimismo atribuye a la existencia de varios puentes vinculados a las calzadas y acueductos de época romana en el entorno de El Puerto y La Puente los errores geográficos al describir la zona, siendo muy similares ambos topónimos.
} 


\section{LOS ORÍGENES: RECONQUISTA Y REPOBLACIÓN CASTELLANA (I 260-1369)}

No vamos a insistir aquí en cuestiones generales acerca de la reconquista castellana de la bahía, por lo demás aspecto ya tratado por otros autores con mayor profundidad (GONZÁLEZ, 1983 y 1999). Tras la conquista de Sevilla en 1248, las huestes castellanas debieron realizar incursiones hasta estas costas durante la década de los cincuenta del s. XIII, estando quizá la ciudad almohade ya en un estado de semi-abandono y manifiesta indefensión (quizá fruto de las razzias castellanas de 1234). Entre 1255 y 1257 el avance alfonsino parece que fructificó en la anexión de importantes enclaves como Xerez, Arcos, Lebrija, etc..., reprimiendo además la rebelión de su hermano el infante don Enrique, que al huir hacia el sur nos informa a través de la crónica regia que hacia 1259 el Puerto de Santa María "non era aun poblado" (CLAVIJO, 196I: 109). La ocupación de Cádiz y el entorno de la bahía se haría efectiva a partir de 1260, impulsándose especialmente desde 1263 la repoblación de la capital y de El Puerto de Santa María, posiblemente amoldándose en buena medida a las áreas administrativas preexistentes. La década de 1265 I 275 sería de cierta estabilidad, salvada la crisis mudéjar ( I264- | 265), y permitiría consolidar el tímido proceso repoblador gaditano (GONZÁLEZ, 1983: II), recibiendo las localidades de la bahía pequeños contingentes poblacionales. En relación con el caso del término de La Puente, objeto central de nuestro trabajo, la situación que describíamos en el apartado precedente parece que tuvo cierta continuidad en los primeros pasos de la repoblación castellana de la bahía en base a dos testimonios reales:

"Don Alfonso por la gracia de Dios, Rey de Castilla, de Toledo, de León, de Galicia, de Sevilla, de Córdoba, de Murcia, de Jaén y de Algarbe. Al concejo de Sanlúcar, e de Rota, e de Sidonia, e de la Puente salud e gracia (...).

Sepades que porque la ciudad de Cádiz, sea más honrada y mejor poblada, tuve por bien que estos nuestros logares sobredichos que fuesen su tér- mino. Otro si tengo por bien y mandovos que cada un Concejo de vos, que escogedes en vuestros logares, omes buenos, dos por Alcaldes e uno por alguacil, a tales que sean buenos para ellos; ende sin embiallos a Cádiz y los de Cádiz confirmarlos. E mando acaecieren algunos pleytos entre vos, id a juicio a vuestros alcaides y el que se agraviare de el juicio, alzase a los alcaldes de Cádiz e dende a mí, e ninguno non sea osado de lo fozer en otra manera, ni de se alzar a otro logar, e cualquier que lo fiziere el cuerpo y a cuanto que oviere, me tornara por ello. Dado en Arcos, el rey lo mandó. Martes 6 de noviembre. Era de 1306. Fernán Martínez la fizo, por mandado el Maestre Fernán Scafia, Arcediano de Niebla". (tomado de CLAVIJO, 196I: II5).

"Don Alfonso por la gracia de Dios, Rey de Castilla, de Toledo, de León (...) Al Consejo de Solúcar e de Rota salud e gracia.

Bien sabedes de cómo yo tuve por bien, que Solúcar, e Rota, e Sidonia, e la Puente, fuesen término de Cádiz, por que la villa fuese más honrada, e mandé que cada una de vos, en vuestros logares, que recogedes dos omes buenos por alcaldes e uno por alguacil, e los alcaldes de Cádiz, que vos los confirmasen, y cuando alguno se agraviase de vuestro juicio, que tomasen las alzadas para ante los alcaldes de Cádiz y de ellos a mí. E agora el concejo de Cádiz embiáronme a decir que faziades vos por nos de vuestros alcaldes, e que non queriades ir a ellos, que vos los confirmasen, ni las alzadas, que las non queriades embiar allá, ni queriades fazer lo que yo mandé, e que metiades y escusa que lo non dexada por al, si non por que non podides pasar la mar cada que queredes, y esta escusa o semejante achaque, ca cuando la mar non pudiessedes passar, carrera aviades por la Puente. Onde vos mando que como quiero que lo fizistis hasta aquí, que de aquí adelante, non sea ninguno alcalde de vuestros logares osado de juzgar pleyto ninguno, harto que los alcaldes de Cádiz, lo ayan confirmado y al que fiziere el pleyto que juzgare non vale, ni alzada para otro logar, non sea dada; i a cualquier que lo fiziere al cuerpo o a cuanto oviese, me tornar a por ello. Dado en Burgos. Jueves 24 día de julio. Era I308. Yo García Fernández la fize escribir por mandato del Rey". (tomado de CLAVIJO, |96|: ||5-||6). 
En ambas disposiciones reales, dadas en 1268 y 1270 , podemos entresacar algunos datos fundamentales sobre la existencia de un «concejo de La Puente» en funcionamiento en fechas tan tempranas integrado (como Rota, Sanlúcar y Medina) en la jurisdicción suprema de Cádiz como parte de su alfoz pero con cierta autonomía. Los indicios disponibles son tenues, si bien cuestiones como la diferenciación de esta área de la isla gaditana tras la reconquista y la perduración del topónimo relativo a la puente invitan a pensar en la cristalización de una realidad rural previa ¿asociada quizá al castillo homónimo?. Algunas informaciones aportadas por Fr. J. de la Concepción ( 1690, libro V) acerca del proceso de deslinde de los terrenos de los nuevos territorios castellanos de la bahía en 1269 arrojan aún más luz sobre la extensión del término de la Puente (fig. 3): "Y de este mojón va por las vertientes por cima del lomo a una cabeza que está sobre las salinas que dicen de Sarraque, onde están unos foyos ${ }^{3}$, y aquí parte término Medina y la Puente de Cádiz y el Portal, de este mojón hasta este a setenta sogas y cinco estadales y de aquí va partiendo Medina con La Puente y atraviesa por las salinas, que dan las salinas a mediodía" y continúa "E va a otro mojón que es la cabeza alta que dicen los moros El Allvergada de Muza Abel, y de aquí parte términos Medina y La Puente de Cádiz y Vejer, y de aquí va partiendo Medina con Vejer" (según ABELLÁN, 2004: 73-74). Estas informaciones no aclaran de forma satisfactoria los lindes septentrionalesoccidentales del término ${ }^{4}$, pero sugieren una gran extensión continental hacia el sur, incluida Chiclana iy quizá parte de Conil? al limitar directamente con Vejer. De cualquier forma, el área donde se situaría la línea territorial con la aldea de El Portal, cercana al caño Zurraque parece indicar que sólo una pequeña porción del actual Puerto Real entraría en el término de La Puente. Por otro lado, la resistencia mostrada por la carta de 1270 a someterse a la jurisdicción gaditana denota cierta vitalidad y conciencia de autonomía de estos incipientes términos de realengo. En relación con esto, un indicio interesante permite suponer la continuidad de la Puente iy su castillo? Como punto viario estratégico, al citar la misiva ante la negativa de los concejos a navegar en la bahía en condiciones desfavorables la posibilidad de que “(...) ca cuando la mar non pudiessedes passar, carrera aviades por la Puente", indicio quizá de que el puente en época alfonsí se hallaba en uso (quizá reparado por los castellanos con enmaderamientos).

El desembarco de los meriníes en 1275 y su rápida actuación militar dirigida hacia el norte de la provincia, con el sitio de Xerez en 1277 y el saqueo del área próxima al año siguiente: Sanlúcar, Rota y al-Qanātir (ien referencia al término de la Puente? ¿Puerto de Santa María y La Puente?). La amenaza sería constante en estos años, siendo de nuevo en 1285 saqueadas las áreas de Xerez, Medina y Vejer. Este continuado estadio de frontera amenazada por los meriníes debió significar un retroceso del proceso repoblador en la bahía, siendo afectadas todas las aldeas que habían dado comienzo al proceso desde 1262. En 1281 le sería otorgada carta-puebla a la localidad de El Puerto de Santa María (GONZÁLEZ, 2002), signo quizá de la estabilización e impulso del proceso en esta zona. En cualquier caso, en relación al término de la Puente, una referencia contenida en un privilegio real otorgado por Sancho IV en I284 indica que los ataques meriníes, si bien debieron dañar al incipiente concejo, no fueron lo suficientemente duros para hacerlo desaparecer:

\footnotetext{
3 Con este término se designa comúnmente una especie de pez de aprovechamiento comercial abundante en la zona, por lo que quizá esta mención haga referencia a la existencia de pesquerías o zonas aptas para ello situadas junto a las salinas.

4 Otro párrafo de Concepción, citado por Clavijo (1961: ||4) informa un tanto confusamente de este límite al norte de La Puente: “...) E ay otro mojón en la cabeça que llaman la Cantera, de grandes cantos e piedra menuda; este mojón parte término entre Cádiz, Xerez y Cidueña, entre el río Guadalete y el Salado, que se contiene la acedía que es de Cádiz, parte término con Xerez y con Medina e con el Puerto, e con la Puente de Cádiz, e todas estas alcarrias están dentro de estos mojones". Cabe preguntarse por la ubicación del topónimo "la Cantera", clave para situar la delimitación (iestará referido a la actual zona conocida como Las Canteras, al suroeste de Puerto Real, área con la que limitan al norte las salinas del Zurraque?). Asimismo, es necesario plantear otra cuestión toponímica capital respecto a la zona mencionada como "la acedía", quizá identificable con la dehesa del Asedía situado en el extremo sur del alfoz jerezano en el posterior territorio de Puerto Real (MARTíN, 2004: 190).
} 
“(...) otrosí, les otorgara que todo vecino de Cádiz o del Logar de la Puente, que non diesen portazgo por mar ni por tierra en todo su señorío, de mercadería que traxesen (...)" (tomado de CLAVIJO, 1961: 122).

Las evidencias disponibles permiten suponer la existencia de una pequeña aglomeración aldeana situada en el entorno del castillo, concentrada en las proximidades de la puente alrededor del camino real entre dicho puente y Cádiz, con jurisdicción sobre ciertas alquerías diseminadas por las áreas de Puerto Real y Chiclana y el resto del territorio insular ${ }^{5}$. Las actividades de este primer núcleo habitacional no debieron diferir demasiado de las tradicionalmente desarrolladas, centrándose en el aprovechamiento agropecuario, pesquero y salinero. De este último aspecto, la mención a las "salinas que dicen de Sarraque" y otras no designadas pertenecientes a su término denotan un temprano aprovechamiento de este preciado bien, que había sido objeto de atención ya en la Antigüedad en relación al intenso comercio conservero (ALONSO, GRACIA y MENANTEAU, 2003) y que se mantendrá como una de las principales actividades económicas de la isla en toda la etapa bajomedieval (FRANCO SILVA, 1997) y moderno-contemporánea (BERNAL ET ALII, 2003: I57160). Es probable que la edificación o reedificación del castillo, por iniciativa real y como centro de poder del concejo de la Puente, fuera acometida en estas décadas finales del s. XIII con el doble objetivo defensivo y de control y como centro de poder del incipiente distrito jurisdiccional. La ubicación de este poblado de la Puente, coincidiendo con las afirmaciones de Clavijo (1961: 116), parece debió situarse a lo largo del camino en el área sur-suroeste de la fortaleza, zona delimitada actualmente por las calles Real, Colón-Escaño y solar de Tallapiedra (fig. 4) según indican las fuentes arqueológicas, contando quizá con edi- ficios de cierta talla dedicados a funciones públicas y religiosas.

Sin embargo, a pesar de la consolidación de este concejo en la recta final de la centuria, la integridad de su término no sería respetada por la corona, que desde los inicios del s. XIV fragmentó en al menos dos ocasiones el gran alfoz de La Puente, dando lugar a las donaciones a casas señoriales de las áreas continentales del mismo. En primer lugar, en 1303 el concejo debe acatar la cesión a Alonso Pérez de Guzmán por parte del rey Fernando IV de la incipiente aldea de Chiclana y sus términos:

"En el nombre del Padre, e del Fijo, e del Espíritu Santo, que son tres Personas e un Dios, e de la Bienaventurada Virgen Gloriosa Santa María, su madre, a quien Nos tenemos por Señora, e por avogada, e por ayudadera en todos nuestros fechos.

Porque entre las creaturas que Dios fizo, sennaló el ome, e dio entendimiento para conocer bien e mal; el bien, porque obrase por ello, e el mal por sauerse de ello guardar. Por ende, todo grand Sennor es tenudo a aquel que obrare por el bien del facer bien, e del dar buen galardón por ello e non tan solamientre por lo de aquel sennero, mas porque todos los otros tomen ende enxiemplo, que con bien fazer venze ome todas las cosas del mundo e las torna a sí.

Et por ende queremos que sepan por este nuestro privilegio los omes que agora son e serán daquí adelante, como nos, Don Fernando, por la grazia de Dios, Rey de Castiella, de León, de Toledo, de Galicia, de Seuilla, de Córdova, de Murcia, de Jahén, del Algarue, e Señor de Molina, por grand voluntad que hauemos de fazer mucho bien e mucha merced a don Alfón Pérez de Guzmán, nuestro vasallo e por los grandes seruicios e buenos que fizo a los reyes donde nos venimos, e fizo a nos, después que nos regnamos acá, et señaladamente por la guarda e et

5 Respecto a la extensión del término de La Puente en la etapa previa a la enajenación señorial de Chiclana en I303, es necesario señalar su limitación meridional con el amplio alfoz vejeriego, según recogen sus repartimientos de I288 y 1293 (LADERO y GONZÁLEZ, 1977), lindando directamente con la alquería de Gelyn, situada al oeste de Chiclana (BUSTAMANTE, 1998: 278), y posiblemente otras como Benafoçin o Cortes situadas algo más al sur. 
amparamiento que la gente ha en las fortalezas que él fizo en los logares que él a en la frontera en que pueblan e guarecen los omes do non solien fasta aquí, dámosle la aldea que dicen Chiclana, que está yerma, que es en término de la Puente de Cádiz, pora que faga y puebla e fortaleza qual él quisiere. Et dámosgela bien, e complidamientre con todos sus términos, con montes e con fuentes, con ríos, e con pastos, con entradas e con salidas, e con todos sus derechos, e sus pertenencias, quantas a e deuie hauer, assí como mejore más complidamientre fue en el tiempo que ella era poblada. Et otorgámosle que la aya libre e quita por juro de heredat para siempre jamás pora él, e pora sus fijos, e por sus nietos, e pora otros qualesquier que los suyos ovieren de heredar, pora dar, e bender, e empeñar, e camiar, e enagenar, e pora facer della, e en ella todo lo que quesiere, así de lo suyo mismo, salvo que no poda facer ninguna destas cosas con Eglesia, ni con Orden, ni con Omes de religión, nin de fuera de nuestro Señorío sin nuestro mandato. (...) Et porque esto sea firme e estable, madamos seellar este privilegio con nuestro sello de plomo. Fecho el privilegio en Badalloz, quince días andados del mes de mayo, en era de mil e trecientos e quarenta e un año. Et nos, el sobredicho Rey Don Fernando, regnant en uno con la Reyna Doña Constanza, mi mugier, en Castiella, en León, en Toledo, en Gallicia, en Seuilla, en Córdoua, en Murzia, en Jaén, en Baeza, en Badalloz, en el Algarue, e en Molina, ortorgamos este privilegio e confirmámoslo". (tomado de BOHÓRQUEZ, 1996: 103-104).

Pocos años después, sería la alquería de Rayhana y sus términos (identificada en el actual barrio Jarana de Puerto Real por J. A. Ruiz Gil - 1994- $)^{6}$ el área desligada del concejo de la Puente por mandato del monarca Alfonso XI en 1335, evento del cual se conservan varios documentos relativos a la donación y su confirmación definitiva en 1338 a favor del noble Gonzalo Díaz de Sevilla:
"En el nombre de Dios, Padre é hijo y Espíritu Santo, que son tres personas é un Dios verdadero, que vive é reina por siempre jamas, é de la Virgen gloriosa Santa Maria su Madre, que nos tenemos por Señora, é por abogada en todos nuestros hechos é á honrra é á servicio de todos los Santos de la Corte Celestial, queremos que sepan por este nuestro privilegio todos los homes que agora son é serán de aquí adelante, como nos Don Alfonso, por la gracia de Dios, rey de Castilla, de Toledo, de Leon, de Galicia, de Sevilla, de Córdoba, de Múrcia, de Jaen, del Algarbe, é Señor de Molina, en uno con la Reina Doña Maria, mi muger, é con nuestros fijos el infante don Pedro primero y heredero, vimos una carta de donación que hicimos á Gonzalo Díaz de Sevilla, nuestro criado del Alcarria de Rayhana, que dice en esta guisa: Sepan cuantos esta carta vieren, como nos Don Alfonso por la gracia de Dios, Rey de Castilla, de Toledo, de Leon, de Galicia, de Sevilla, de Córdoba, de Murcia, de Jaen, del Algarbe é Señor de Molina: Por hacer bien é merced á vos Gonzalo Diaz de Sevilla, nuestro criado é vasallo de Don Pedro, mio hijo, por mucho servicio que nos habedes fecho y facedes cada dia, é señaladamente, por cuanto servicio nos facedes cada dia, en la crianza del dicho Don Pedro, mio hijo, damos vos el Alcarria, que diz de Rayhana, que es en el término del Castillo de la Puente de Cádiz, é damos vos la como parte con Medina Sidonia, é con Chiclana, é con las aguas dulces, esta dicha Alcarria vos damos con todas sus tierras, é con sus montes, é con las aguas, é con sus prados, é con sus pastos, é con todas sus pertenencias cuanto ha é haber debe de fecho, é de derecho, é damos vos, la esta dicha Alcarria como sobre dicho es por juro de heredad, para vender y empeñar y cambiar y enagenar, é para facer de ella, todo lo que vos quisiéredes, así como si fuere cosa propia vuestra, de vuestro patrimonio, salvo ende que ninguna de estas cosas, non podades facer con home de orden ó de religion, ó de fuera del nuestro Señorío, sin nuestro mandado, é por esta nuestra carta defendemos firmemente, que nin-

6 J. Abellán afirma por el contrario que dicha alquería se encontraba situada mucho más al sur, en el límite de los actuales términos de Chiclana y Puerto Real, al sur del caño salado denominado Zurraque, en el área del "Pinar de los Franceses" (ABELLÁN, 2004: 75), en virtud de las informaciones transmitidas por el amojonamiento de 1269. 
guno ó algunos sean osados de embargar desta dicha heredad, ni parte de ella, á vos el dicho Gonzalo Diaz, ni al que la obiese de recaudar por vos, si no sepan que cualquier que algun embargo en ellos vos pusiesen, ó contra ello vos fuesen, ó pasasen en cualquier manera, habria nuestra ira, é a ellos é á los sus cuerpos, nos tornariamos por ellos, é de esto vos mandamos dar en nuestra carta, sellada con nuestro sello de plomo á 18 dias de Mayo Era de 1373 años. Yo Alfonso Martínez la fiz escribir, por mandado de Rey. Ruimartinez, Andrés Gonzalez; vista Domingo Perez. Donis Fernández". (tomado de CRISTELLY, I89 I: 41; también reproducido en FRANCO SILVA, 1995: 75).

"Vimos otra carta del concejo del Castillo de la Puente de Cádiz, que dice en esta guisa: Domingo 17 días del mes de Mayo, era de 1376 años, estando en el concejo del Castillo de la Puente de Cádiz, ayuntados á campana llamados en la capilla de Santa Maria, que es dentro en el dicho castillo, Gonzalo Diaz de Sevilla, criado de nuestro Señor el Rey, é vasallo de Don Pedro su hijo, dijoles en como el dicho Rey, que mantenga Dios á su servicio muchos años y buenos, que le había dado una alcarria que dicen de Rayhana, que caía en el término del dicho Castillo de la Puente, é que tuviesen por bien demandar, luego leer la carta de la donación, que el dicho Señor Rey le había mandado dar al dicho Gonzalo Diaz. En esta razon y los homes buenos del Consejo, mandáronlo luego leer la dicha carta á Martín Diaz, su escribano por nuestro Señor el Rey, el tenor de la cual carta leida, en respondiendo á ella dijeron, que toda merced que el dicho Señor Rey hacia al dicho Gonzalo Diaz, que les placía ende mucho por muchos deudos, muy buenos que ellos habían con el dicho Gonzalo Diaz é obieron otrosí con su Padre Diego Rodríguez que Dios perdone, é mandaron luego los dichos homes buenos del concejo del Castillo de la Puente de Cádiz, á Miguel Pérez su alguacil, que estaba delante é ellos presente, que fuesen luego otro día, el Lúnes siguiente con el dicho Gonzalo Diaz á la dicha Alcarria de Rayhana y que le entregasen é le pusiesen en posesion de ella, para que fuese suya de dicho Gonzalo Diaz, ó de quien él quisiese de aquí adelante, como nuestro Señor el Rey que la deslinda por la carta de la donación que el dicho Señor Rey le dio, como sobre dicho es, y de ello todo es como pasó y en como los homes buenos del concejo del Castillo de la Puente de Cádiz, le mandaron entregar la dicha Alcarria de Rayhana, pidiéndoles el dicho Gonzalo Diaz, que le mandasen dar su carta del dicho concejo, é que mandasen á Martín Diaz su escribano, que la signase con su signo, é los dichos homes buenos del concejo tuviéronle por bien e mandaronle dar luego esta su carta sellada con su sello de cera, colgado é signado del signo del dicho Martín Diaz su escribano público por nuestro Señor el Rey, é mandaron á los homes buenos, que en fin de esta dicha carta, pusieren sus nombres en ella, en testimonio de verdad, fecha en el dia y en la era sobre dicha. Yo Martín Diaz escribano público de la Puente de Cádiz, la fiz escribir é fice mio signo. Fernando Diaz y Gonzalo Perez el Mozo". (tomado de CRISTELLY, I89I: 42; también reproducido en FRANCO SILVA, 1995: 76).

Los documentos relativos a esta cesión nos aportan un precioso conjunto de datos relativos al estado del concejo isleño en las primeras décadas del s. XIV: por un lado, en el documento de 1335 se cita por vez primera la existencia del «Castillo de la Puente de Cádiz», y confirma la extensión del término del concejo por aquellas fechas incluyendo el área insular y la zona del actual Puerto Real lindando directamente con el Guadalete, Medina y Chiclana, desligada del mismo término algunas décadas antes a favor del señorío de los Guzmán. Por otro, el texto de confirmación de 1338 nos confirma la existencia del dicho castillo, afirmando además que la capilla dedicada a Santa María que en él se hallaba servía de lugar de reunión al concejo de la Puente de Cádiz, uniendo claramente los destinos de fortaleza y ente municipal. Asimismo, el documento sugiere una consolidación del núcleo aldeano isleño, al existir no sólo una sede importante como el castillo para el poder del concejo, sino también funciones civiles destacadas como la escribanía pública en este caso ostentada por Martín Díaz. A pesar de las pérdidas territoriales del primer tercio del siglo, parece claro a tenor de estos testimonios que el poblado generado con el impulso repoblador alfonsino se consolidó y desarrolló considerablemente en estas décadas, probablemente gracias al alejamiento de la 
frontera y a la continuidad de la explotación agropecuaria-pesquera. Ocho años más tarde, el mencionado Gonzalo Díaz de Sevilla renunciaría a su posesión, que en documento otorgado en la propia escribanía de la Puente de Cádiz en noviembre de 1344 afirma devolver a los moradores de la dicha Puente y de Cádiz, en un documento que ha suscitado no pocas controversias sobre su autenticidad al tener difícil explicación la alusión a Cádiz y su jurisdicción (vid. ZURITA, 1947: 228-229):

"Sepan cuantos esta carta vieren como yo Gonzalo Diaz de Sevilla, criado del Rey y Alcaide de Medina Sidonia por mi Sra. Doña Leonor; otorgo é conozco que por razon de la donación que me hizo el dicho Señor Rey y los homes buenos del concejo de la Ciudad de Cádiz, de la Alcarria de Rayhana, según se contiene en las cartas de las donaciones del dicho Señor Rey é del concejo de la Ciudad de Cádiz; en esta razon otorgo á los vecinos e moradores de ella que agora son, serán de aquí adelante para siempre jamás, é á los vecinos é moradores de la Puente de Cádiz, en nombre de Cádiz que ellos que puedan facer en la dicha alcarria y en su término casas y viñas de labor y pacer las yerbas y beber las aguas é cortar montes é todas las otras cosas de que se puedan aprovechar por mar é por tierra, así como de lo suyo mesmo, é ademas, que la jurisdicción de la dicha alcarria que sea de la de Cádiz, por nuestro Señor el Rey, cuya es de quien yo ove esta dicha donación é juro é prometo por el nombre de Dios, é por los Santos evangelios, en que puso las manos corporalmente de no ir, ni pasar contra esto que dicho es, ni contra parte de ello, ni otro por mí en ningun tiempo, por ninguna manera, ni quien lo mio heredase, é si lo ficiese, que me non vala, é pido merced al mio Señor el Rey Don Alfonso, é á los otros Reyes que serán después de él, que lo guarden y lo fagan guardar como dicho es, é porque esto sea firme é non venga en duda, di vos esta carta mia de cuero sellado con mio sello de cera pen- diente, é firmado de mi nombre. Fecho postrimero dia de Noviembre Era de 1382 años. Testigos, Miguel Perez, Alguacil, é Garcia Perez. Yo Gonzalo Diaz. Yo Martín Diaz, escribano de la Puente de Cádiz á otorgamento del dicho Gonzalo Diaz é fice aquí mio signo é los testigos". (tomado de CRISTELLY, I89I: 44; también reproducido en FRANCO SILVA, 1995: 79).

Sea como fuere, la jurisdicción sobre el área puertorrealeña debió revertir de nuevo en el Concejo del Castillo de la Puente de Cádiz, si bien quizá este documento, la extraña e injustificada renuncia de Gonzalo Díaz a su nuevo dominio y la adición a la tradicional nomenclatura "Concejo de la Puente" de la terminación "de Cádiz" quizá indiquen un creciente interés de la principal ciudad de la bahía por reintegrar totalmente estos territorios a su dominio jurisdiccional. Tras estos sucesos, pocas referencias tenemos sobre el concejo isleño, si bien testimonios como el contenido en la crónica de Alfonso XI nos muestran la participación del mismo en el abastecimiento de las campañas contra Algeciras y Gibraltar:

"Et el rey sintiéndose mucho de esto, estido ocho días que non quiso comer carne, diciendo que pues los sus vasallos tanto lazoeraban, que la non comeria fasta que Dios diese tiempo con que podiesen venir las viandas. Et fue la merced de Dios de dar buen tiempo qual lo avian menester, et vinieron todas las barcas que estaban cargadas de viandas, cerca de Tarifa, et de Barbate, et al puerto de Sancto Pedro. Et de allí en adelante oviera la hueste de los cristianos abondamientos de viandas por el tiempo que y estidieron" (pág. 253 de las crónicas de Alfonso $\mathrm{XI}$, tomado de CLAVIJO, I96I: I I7).

Esta mención a un área portuaria situada en el caño de Sancti Petri ${ }^{7}$, seguramente ubicada en las proximidades del puente, quizá haga referencia a nivel más genérico a las activida-

\footnotetext{
7 Dicha información ha dado pie a algunos autores como Clavijo (1961: I |7- | | 8) a plantear la existencia en territorio insular de una alquería situada en la ribera del caño quizá en el área de Gallineras-Cerro de los Mártires. Es lógico pensar en la existencia de alguna aldea o diversas explotaciones rurales más pequeñas situadas en la zona centro-sur del área insular del término de La Puente, quizá concentradas entorno al actual puerto de Gallineras, posiblemente en uso desde época romana y con amplios despoblados alrededor muy aptos para la explotación agropecuaria así como esteros utilizables para la pesca y la obtención de sal.
} 
des marítimas desarrolladas en las riberas de este caño por las alquerías y aldeas próximas (como Chiclana o Rayhana) y no sólo al núcleo de la Puente, pero con seguridad referencia la participación del concejo de realengo isleño y su alfoz en el sitio de Gibraltar por el monarca castellano. Este abastecimiento de viandas al ejército sitiador señala un cierto nivel de producción excedentaria agropecuaria y pesquera en este concejo, continuando con las actividades subsistenciales ya desarrolladas décadas atrás. Nuevas referencias, en esta ocasión del reinado de Enrique II certifican el carácter de vía acuática de primera magnitud del Caño de Sancti Petri:

“(...) pasando a Santo Petro, entraron en el estrecho de Gibraltar [las galeras] é llegaron a la villa de Tarifa, donde estaba el buen caballero Martín Fernández Portocarrero (...)" (según CLAVIJO, 1961: 128, Crónica de Pero Niño).

Pero los sucesos derivados de la guerra entre castellanos y portugueses iban a modificar el orden descrito anteriormente. Los documentos relativos a la cesión del señorío de La Puente a Juan Sánchez de Suazo entre 1408 y 1420 muestran con claridad cómo el ataque portugués sobre la bahía acaecido en 1369 debió tener un efecto devastador, al menos en el caso del poblado, puente y castillo isleños. En efecto, según se ha puesto de relieve (VALDEÓN, 1966: 222-226 y 244-245; SÁNCHEZ HERRERO, 1986; FRANCO SILVA, 1995: 14-15), la isla gaditana fue asaltada por una flota lusitana compuesta por 30 naos y 28 galeras junto a otras cuatro galeras genovesas, que probablemente centrarían sus correrías en la desprotegida isla y la pequeña fortaleza junto a la puente. En un episodio bien sintetizado por A. Franco Silva para el caso isleño, a partir de 1370 el empuje de la flota castellana al mando de Ambrosio Bocanegra rechazaría la flota invasora del Golfo de Cádiz, que había dado lugar a la destrucción atestiguada aún varias décadas después en la donación de |4| I: "(...) é que por quanto la dicha casa está agora desipada y derribada las almenas della la qual disen que derribaron los echamoros [chamorros] en vida del dicho rey don Enrique mi visabuelo y otrosí está en la dicha casa mui mucho de reparar de manera que de pre- sente no rinde cosa alguna, por quanto decides que las viñas y salinas que en ella avian que son perdidas en tal manera que no hay propios algunos que rinda cosa alguna saluo la barca que puede rendir fasta quinientos maravedis (...)" (FRANCO SILVA, 1995: 14-15). ¿Cómo afectó realmente este hecho bélico a las localidades del entorno de la bahía?. No lo sabemos con certeza, pero ciñéndonos al caso de La Puente, fortificada sólo con el viejo castillo y carente probablemente de cerca alrededor del poblado, con múltiples asentamientos rurales desprotegidos en su alfoz, los efectos debieron ser enormemente negativos. Varios datos, conjugando la información arqueológica y la documental, parecen señalar con claridad este extremo, que daría fin a su entidad como unidad de poblamiento significativa en la bahía. Por un lado, las excavaciones llevadas a cabo en el castillo de La Puente (fig. 5), lugar de reunión del concejo y sede de la capilla de Santa María (iiglesia parroquial?) confirman las labores destructivas acometidas por los portugueses, documentándose en el relleno de la zona sur-oeste de la cava defensiva restos del proceso (figs. 6-7): algunas armas, materiales constructivos, restos de bolaños, etc... arrojados con anterioridad o en época de los Suazo a su interior (SÁEZ, TORREMOCHA y SÁEZ, 2004 y e.p. a-b). Los restos muebles documentados nos informan de un asedio y posterior incendio de la fortaleza, con el añadido proceso de desmochar las almenas quizá realizado de forma sistemática como signo de dominio sobre ella o fruto de su ruina bajo las llamas. Los bienes y archivos contenidos en el castillo debieron ser saqueados o también quemados, incluyendo la citada capilla de Santa María, así como el poblado anexo a la fortaleza. Asimismo, el propio reaprovechamiento del obsoleto foso como cantera para la extracción de sillarejo de ostionera previamente a su colmatación denota una actividad reconstructiva de peso (SÁEZ, TORREMOCHA y SÁEZ, e.p. b). Por otro lado, el puente, que según atestigua el documento de 1270 debía estar en funcionamiento y que Juan Sánchez de Suazo hubo de reconstruir a inicios del s. XV en paralelo al uso de una barca de pasaje situada en las inmediaciones (FRANCO SILVA, 1995: 14). Asimismo, la existencia de huertos y salinas arruinadas ("Ias viñas y salinas que en ella 
avian que son perdidas"), explotaciones que como en anteriores apartados mencionamos, estaban ya en funcionamiento desde la etapa islámica. Finalmente, un argumento ex silentio, la ausencia de nuevas referencias al concejo de La Puente en los años posteriores al ataque y la cesión casi inmediata del término y de la ya denominada "casa" a nobles de las familias jerezanas Vera y Suazo parecen señalar la total ruina económica y poblacional de La Puente tras el evento y la necesidad de dar un nuevo impulso a su poblamiento a través de estas donaciones (MÓSIG, 2004: 26) con el fin de fortalecer un punto viario tanto destacado como el único acceso terrestre a la isla gaditana.

\section{EL PASO AL RÉGIMEN SEÑORIAL: LOS VERA Y LOS SUAZO}

El ataque de 1369 se configura por tanto como un punto de inflexión clave en la historia de La Puente y de su castillo, dando fin a su autonomía bajo el dominio de la corona para pasar en estas décadas subsiguientes a formar parte de sucesivos señoríos nobiliarios de origen jerezano. En esta etapa, en que a iniciativa de estos nuevos señores el término intenta remontar el vuelo de nuevo, con la reactivación de las explotaciones agropecuarias y salineras y la reconstrucción del castillo y el puente, la antigua Puente de Cádiz (designada de Suazo a partir del s. XV) se enfrentará a las ansias expansionistas de Cádiz y Xerez, lucha que terminará con la configuración definitiva de su alfoz reducido al territorio insular. Pocas novedades sobre lo ya dicho por otros autores podemos aportar en esta época, excepto las inferencias derivadas de las excavaciones en el castillo isleño, por lo que en buena medida sintetizaremos a través de las fuentes documentales disponibles los sucesos históricos de este periodo de transición.

\section{La cesión a Alfonso García de Vera (1370-1408)}

La donación del señorío de La Puente a Alfonso García de Vera, miembro de una de las más destacadas casas nobiliarias de Xerez (SÁNCHEZ SAUS, 1996 y 1997), nos es conoci- da gracias a las referencias que en documentos de comienzos del s. XV se contienen en referencia al traspaso de este mayorazgo a Juan Sánchez de Suazo entre 1408 y | 420. Un fragmento de dichos documentos arroja luz sobre la cuestión:

Yo el rey por hacer bien y merced a vos Juan Sánchez, bachiller oydor de la mi audiencia, por muchos seruicios y buenos que ficistes al rey mi padre y mi señor que Dios dé Sancto paraíso y a mi facedes de cada dia y al infante don Fernando mi tío y mi tutor estando residentemente en el su concejo en lo que a mi servicio cumple fago a vos merced y pura donación de todo el señorío y derecho de propiedad y posesión que yo é y a mi pertenece auer en la casa que disen de la Puente con la barca que cerca della está la qual es en la Ysla de Cádiz por quanto me dijistes que el rey don Enrique mi visabuelo que Dios perdone ficiera merced y donación de la dicha casa y barca con todo su término y señorío y pertenencias y derechos y suelos a Alfonso García de Bera, vecino de Xeres, el qual decides que tobo y obo la dicha casa y barca por la dicha razon y despues que la empeñara a otras personas que la an tenido por razon de ciertos empeñamientos y ventas que della fueron fechos e que el dicho Alfonso Garcia finó y no dejó fijo ni fixa lexitimo heredero que por lo qual el señorio de la dicha casa y barca es a mi debuelto segun que de antes era de los reyes donde yo bengo e por ende fagos bos la dicha merced de todo el señorio y derecho que a mi pertenece o pertenecer deve en qualquier manera en la dicha casa y barca y término della, es mi merced que la hayais según que mejor y mas complidamente la obo e poseió el dicho Alfonso García de Vera con sus pertenencias por virtud de dicha merced e para que la bos ayades y los que lo buestro obieren de hauer y de heredar por manera de merced y de donación y mayorazgo que dello os fago e del derecho que yo é en la dicha casa y en sus términos y pertenencias y mando al concejo de Xerez y de Cadiz mis ziudades que vos consientan usar del señorio que yo he en la dicha casa y a mi pertenece y perteneció despues de la muerte del dicho García de Bera e según que mejor e mas complidamente la obo el dicho Alfonso García su padre por virtud de la dicha donación. E mando 
al mi chanciller maior y a de los que estubieren a la tabla de los mis sellos que vos den y libren y sellen mis cartas y privilegios los que menester obiéredes en esta razón. Fecha en la villa de Valladolid en catorce dias e noviembre año del nacimiento de nuestro Señor XesuXristo de mill e quatrocientos y ocho años. Yo Ferrand Alfonso la fize escribir por mandado de los señores reyna y ynfante tutores de nuestro señor el rey y rexidores de sus reynos. Yo la reyna. Yo el infante. Rexistrada. (texto contenido en la confirmación de la donación otorgada en 1420, extraído de Franco Silva, 1995: 80-8I)

De estas informaciones transmitidas por la donación a los Suazo, vemos cómo el señorío de La Puente fue propiedad de Alfonso García de Vera y más tarde de su hijo García de Vera hasta su reversión a la corona previa a la donación en 1408 a Suazo. Según Franco Silva (1995: 15), Fernando de Vera, hermano de García e hijo del primer señor de La Puente, intentó mantener para sí el dominio sobre este señorío ocupando incluso en I 408 aún la ahora casa fuerte de la isla, entrando en pleito con la disposición real hasta su renuncia a sus derechos en 1410. Al margen de estas informaciones sobre la tenencia del castillo y su territorio jurisdiccional, así como del barcaje sobre el caño, no disponemos de elementos que nos ayuden a definir la suerte del poblado del antiguo concejo de la Puente (fig. 8), cuya existencia parece desvanecerse desde I 370. Incluso desconocemos la fecha exacta de la donación a los Vera, que algunos autores sitúan en 1377. Asimismo, el documento habla acerca de que el dicho señor de la Puente no debió prestar demasiado atención sobre su nueva posesión, probablemente por la ruina de la misma, la escasa o nula población y la práctica inexistencia de beneficios económicos, declarando que "despues que la empeñara a otras personas que la an tenido por razon de ciertos empeñamientos y ventas que della fueron fechos", señalando el nulo interés por la explotación directa de sus nuevas propiedades. En efecto, algunos documentos muy posteriores informan que se tiene constancia de la existencia de una "escrip(tur)a de venta que celebró essa II(ustrí- si)ma ciudad en 2 de $\mathrm{Ag}$ (os)to de 1399, a favor del II(ustrísi)mo Cavildo Ecc(lesiásti)co y de Fernan Gonzalez de Vrdiales, que compran de mancomun el Lugar de la Puente con todas sus pertenencías, mero míxto imperío, derechos de Barcages (...)". El Cabildo y doña Juana Ximénez (viuda de Urdiales) vendieron en septiembre de ese mismo año la propiedad a un tal Juan Rodríguez de Faria(s), al parecer sevillano ilustre. Asimismo, dicho documento señala que en esta recta final del s. XIV "havían poseído el dicho Lugar, Rodrigo de Foyos [o de Hoyos] y Ines Fernan su muger, que tambien pertenecen a la nobleza antigua de Sevilla". En cualquier caso, esta sucesión de propietarios confirma la información contenida en el documento de 1408 y la inexistencia de un interés real de los Vera en la isla. Es posible que su concesión estuviese relacionada con una compensación relativa al apoyo de los Vera hacia Enrique II en el concejo jerezano durante la contienda civil castellana, pero probablemente también influyó la necesidad de volver a crear un dominio que ayudase a contener los choques territoriales de los concejos de Cádiz y Xerez, separados únicamente por La Puente, y que terminarían derivando en el s. XV hacia el área de Matagorda del actual Puerto Real (MARTíN, 2003: 153). El interés de algunos particulares en adquirir el Lugar de la Puente, con el puente arruinado pero en funcionamiento la barca que más tarde sería recogida en el documento de cesión a los Suazo, y con un castillo ciertamente dañado pero aún habitable (como demuestra en hecho de que Fernando de Vera lo ocupase), muestran tímidamente cómo quizá, a pesar de sufrir los duros efectos del ataque portugués, el poblado isleño quizá continuó sensiblemente disminuido siendo habitado y explotado por un reducido número de vecinos, insuficientes ya para tener concejo propio (algo que no de nuevo sucederá hasta fines del XVI -FRANCO SILVA, 1995: 72-). En cualquier caso, se trata de unas décadas de clara recesión demográfica y de crisis económica para el lugar de La Puente, y lo que es más significativo, su práctica desaparición como localidad autónoma en el contexto de las pugnas territoriales de la bahía gaditana. 


\section{La donación de La Puente a los Suazo (1408-1490)}

El monarca castellano Juan II, aparentemente con la exclusiva oposición de los Vera (¿y acaso del concejo gaditano?) donó al doctor Juan Sánchez de Suazo el castillo y su término, incluyendo la barca situada en las cercanías del puente, en varios documentos otorgados entre 1408 y 1420 (FRANCO SILVA, 1995), dando lugar a un señorío que se extendería hasta finales de la centuria:

Yo el rey por facer bien y merced a vos Juan Sánchez doctor oydor de la mi audiencia que por muchos seruicios y buenos que me auedes fecho e fecedes de cada dia porque me digistes que yo que vos obiera fecho merced en el año que pasó de mill e quatrocientos e ocho años quando vos embié en Aragón por mi embajador sobre algunos negocios de los reynos de Castilla e de Aragón al rey don Martín mi tio que Dios perdone e donde a la ciudad de Pisa sobre los fechos de nuestro señor el papa Benedicto al ayuntamiento de los cardenales y de los prelados que se y acordaron que vos hiciera merced de la casa de la puente que es en la ysla cerca de Cádiz la qual auia seydo primeramente de Alfonso Garcia de Bera vecino de la ciudad de Xeres por merced y donación que della le auia fecho el rey don Enrique mi bisabuelo que Dios perdone con todos sus términos y pertenencias y con la justicia ciuil y criminal alta y baja, el qual Alfonso Garcia la tomo por suya y ansi como suya y usó della y de los dichos términos y pertenencias y justicia ciuil y criminal que en la dicha casa y términos pertenecen en quanto la tobo y poseyó, e después de sus dias que Garcia de Bera su fijo maior que la tobiera e poseyera el qual dis que morió sin fixo lexitimo heredero por lo qual se tornó la dicha casa con sus términos e pertenencias a la mi corona, la qual merced desides que vos fize por manera de mayorzago, é que por quanto la dicha casa está agora desipada y derribada las almenas della la qual disen que derribaron los echamoros [chamorros] en vida del dicho rey don Enrique mi visabuelo y otrosí está en la dicha casa mui mucho de reparar de manera que de presente no rinde cosa alguna, por quanto decides que las viñas y salinas que en ella avian que son perdidas en tal mane- ra que no hay propios algunos que rinda cosa alguna saluo la barca que puede rendir fasta quinientos maravedis de esta moneda, e que es buestra intencion de facer reparar la dicha casa $y$ heredad que ella antes auia que fuese mi merced de vos facer puramente $y$ sin condición alguna, y porque vos y los que viniesen de vos podiesen auer prouecho de la dicha casa y sus términos y pertenencias para vos y para los que lo buestro oviesen de auer y de heredar asi por buestro testamento como en otra manera qualquier, e yo por vos facer merced y dar galardón de los servicios que fecistes al rey mi padre que Dios de sancto paraíso y facedes a mi de cada dia como dicho es, e por los grandes afanes que en ello recivistes y recivides es mi merced de vos facer e fago la dicha merced en esta manera que ayades la dicha casa y término y pertenencias y barca puramente para vos y para los que lo buestro ovieren de auer y heredar en qualquier manera y con la justicia civil y criminal de la dicha casa y términos e que vsedes de la dicha casa y termino y propios della cumplidamente y según mejor y mas cumplidamente a mi pertenece la casa y término y según y mejor y mas cumplidamente el dicho Alfonso Garcia en el su tiempo tubo y administró y perteneció auer y administrar a los reyes donde yo bengo e el dicho Alfonso Garcia la tobo y administro por la dicha merced a el fecha, y mando al mi chanciller maior y a los que estouieren a la tabla de los mis sellos que den y libren y sellen mis cartas y priuilegios los que menester hobiéredes por esta razon para maior firmeza de esta merced que yo os fago e esta merced vos fago no faciendo perjuicio alguno a otra persona qualquier que algún derecho aya a la dicha casa. Fecho en treinta dias de agosto año del nacimiento de nuestro Señor XesuCristo de mill e quatrocientos e honze años. Yo Diego Fernández de Vadillo lo fize escribir por mandado de los señores reyna e ynfante tutores de nuestro señor el rey regidores de los sus reynos. Yo la reyna. Yo el infante. Registrada. (texto contenido en la confirmación de la donación otorgada en 1420, extraído de FRANCO SILVA, 1995: 81-82).

En dichos documentos de otorgamiento y confirmación, cinco en total, se relatan la ya mencionada etapa del señorío de los Vera sobre La Puente y el lamentable estado en que 
puente, castillo y heredades se encontraban en el momento de la cesión. Estas cuestiones, así como la transmisión de estos dominios a través de Pedro de Suazo y su hijo Juan de Suazo hasta el trueque con Rodrigo Ponce de León en 1490, han sido ya bien definidos por otros autores (CRISTELLY, I89I; ZURITA, 1947; FRANCO SILVA, 1995: 13-17) en la medida que la escasez documental lo ha permitido. Por ello, no entraremos de nuevo en la relación pormenorizada -remitiendo a los citados trabajosde un periodo que por lo demás puede definirse entorno a un repunte del término gracias a la labor de sus nuevos señores y a un creciente interés de Cádiz por integrar La Puente de Suazo a su alfoz (vid. documento de 1437 referente a la requisa por parte de los gaditanos de barcos cargados de bastimentos para el castillo isleño y protesta del cabildo jerezano, en ZURITA, 1947: 250-25 I). Si el primer Suazo se dedicó hasta su muerte (1435) a la reconstrucción del puente y del vetusto castillo arruinados por la acción de los portugueses décadas atrás, fue sin duda su hijo primogénito Pedro el que mayores lazos tuvo con su señorío, en el que residió durante buena parte de su vida y donde encontró reposo eterno (en la iglesia titulada de San Pedro ${ }^{8}$ ubicada en el propio castillo). A él debemos probablemente la fisonomía final de la casa fuerte reconstruida y el impulso a la explotación de los recursos agrícolas y marinos del término, así como su defensa frente a los intereses gaditanos ganándose el apoyo jerezano tras tomar vecindad en dicha villa el 13 de septiembre de 1437 (ZURITA, 1947: 253). Bajo el mandato de estos dos primeros señores de la familia Suazo se rehabilitaron el castillo y el puente y las actividades económicas debieron reconducirse a parámetros similares a los de la centuria anterior, con la explotación de huer- tas y viñedos, de caños de pesquería y de salinas ${ }^{9}$, proceso de recuperación ya plenamente consolidado en el periodo del tercer Suazo y que se encuentra plenamente documentado para el s. XVI ya bajo el dominio de la casa de Arcos (FRANCO SILVA, 1995: 17-72). Además de las ansias del cabildo gaditano por «recuperar» esta fértil parte de la isla, la riqueza salinera de La Puente y el interés de don Rodrigo por la actividad almadrabera que tantos beneficios daba a la casa rival de los Guzmanes (con quienes mantuvo luchas abiertas desde I469 en parte relativas al monopolio atlántico de éstos, armando la almadraba de Hércules en el istmo) seguramente debieron pesar en el interés del duque de Arcos por el señorío de los Suazo. De cualquier forma, la reversión de Cádiz a la corona en I 493 (LÓPEZ, 1992) frustró de nuevo la integración de toda la ínsula gaditana en un mismo término, quedando el antiguo término de la Puente (ahora conocida como de Suazo) bajo un nuevo régimen señorial.

\section{CONCLUSIONES}

Expuestas las líneas generales de cada periodo de la etapa bajomedieval isleña, plantearemos ahora una serie de valoraciones de conjunto acerca de la secuencia diacrónica del poblamiento desarrollado entre los ss. XIII a XV, sintetizando las informaciones documentales $y$ arqueológicas (fig. 9):

\section{Al-Qantara. El modelo de poblamiento islámico}

Los escasos testimonios escritos y la información arqueológica disponibles señalan cómo el Caño de Sancti Petri se configuró en la etapa

8 Seguramente, la primigenia capilla advocada a Santa María citada en el s. XIV que servía de lugar de reunión al concejo de La Puente, también destrozada a causa del ataque luso de 1369, debió ser reconstruida por los Suazo a comienzos del XV cambiando su advocación por la de San Pedro (io conservando ambas?), siendo la veneración a este apóstol conocida en esta familia no sólo a través de la onomástica sino como demuestra la construcción de una capilla dedicada a dicho santo en la Iglesia de San Francisco de Xerez, a donde se trasladaron los restos de Pedro de Suazo (es significativo a este respecto la referencia contenida en la toma de posesión de I5II, en FRANCO SILVA, 1995: 21).

9 Esto último evidenciado por uno de los documentos obtenidos por el marqués de Cádiz en el proceso de trueque de 1490, referente a "una licencia que dio Jhoan de Soaço como sennor de la puente a Pedro Galindes para cortar ciertos salados del termino de dicho castillo" (en ZURITA, 1947: 255). 
islámica avanzada como un punto de referencia para la navegación del litoral atlántico ibérico, quizá también como lugar de fondeadero y puerto de salida de productos de las alquerías costeras. En paralelo a la recuperación de la Qãdis islámica en la etapa almorávide-almohade, la explotación del territorio insular y de la campiña continental costera se acrecentó e intensificó, testimonio de lo cual son las diversas ocupaciones rurales detectadas en el entorno de la bahía. En San Fernando, los campos de silos y fosas domésticas documentadas en Sector III Camposoto y Campo del Gayro señalan la presencia en la franja central de la isla de una comunidad aldeana dedicada a actividades agropecuarias correspondiente a la etapa almohade. Es bastante probable que dicha actividad principal se complementase con otras como la recolección de sal o la pesca, dos tipos de aprovechamiento económico que por otro lado sabemos estaban ya en marcha en la zona desde antes de la repoblación alfonsina (vid. amojonamiento de 1269), destacando la zona del Sarraque. El término de esta aglomeración rural de la fase almohade, articulada probablemente en torno a un rehabilitado puente y a una fortaleza o almunastir (ABELLÁN, 2004: 73-75) ubicado en el solar del actual Castillo de San Romualdo ${ }^{10}$, incluiría ya parte del territorio de Chiclana y Puerto Real lo que quedaría fosilizado en el alfoz determinado durante el proceso repoblador. Por tanto, al menos a partir de época almohade se configura una primera versión de lo que posteriormente será el término del Lugar de La Puente, con un núcleo central entorno al castillo y el puente y un aprovechamiento rural en forma de alquerías, explotaciones salineras y áreas de pesca.

\section{Las primeras décadas de La Puente de Cádiz (1260-1300), territorio de Realengo}

El abandono de las explotaciones rurales almohades como la documentada en Sector III Camposoto señala, en conjunción con los datos aportados por otros puntos de la bahía, un cese de dicha actividad anterior a la acción repobladora del rey sabio, quizá debidas a las razzias y creciente presencia castellana que desde 1235 y sobre todo en la etapa de Fernando III se cebaron sobre la Yazirrat Qādis. En cualquier caso, las localidades existentes debieron conservar su papel como núcleos articuladores del paisaje entorno a una fortaleza o punto protegido que haría las veces en paralelo de centro económico-político local.

Como antes señalábamos, no sin ciertas dificultades como la oposición del concejo ya establecido en la década de los sesenta del s. XIII, desde los inicios del proceso repoblador el alfoz de La Puente se integró jurisdiccionalmente en el de Cádiz junto a otros como Rota, Medina o Sanlúcar, si bien el control no debió ser demasiado intenso debido a los problemas de la capital derivados de la crisis del proyecto africano de Alfonso $X$. Los textos nos informan de la existencia en este periodo de una sugerente actividad mercantil por vía marítima y probablemente terrestre (como denuncia el hecho de estar el puente en uso, según el documento de 1270), generada no sólo a través del puerto gaditano sino también en el caño de Sancti Petri. Asimismo, la actividad salinera parece que se reactivó a buen ritmo, con la explotación segura del área del caño Sarraque y sus marismas adyacentes, y a buen seguro otras áreas circundantes del término insular propicias

\footnotetext{
I0Algunos indicios sugieren que dicho término debía girar necesariamente en torno a un centro de poder en forma de puesto fortificado, inexistentes en Puerto Real y Chiclana para la etapa islámica; asimismo, la perduración en buena medida de dicho alfoz y de la entidad concejil de La Puente tras los repartimientos alfonsinos también apunta en la misma dirección, pues equipara al asentamiento cercano al puente a otros dotados de fortaleza (Rota, Puerto de Santa María, Sanlúcar...) incluidos en el territorio jurisdiccional de Cádiz, convirtiendo la presencia de un castillo o similar en elemento decisivo para la definición de las cabezas de término del entorno de la bahía tras la reconquista. En cualquier caso, han de ser las intervenciones arqueológicas de los próximos años las que deben matizar los orígenes del castillo.
} 
para su explotación. Respecto a la existencia de aglomeraciones rurales secundarias dependientes del concejo del entorno de la puente, tanto los precedentes almohades como las informaciones derivadas de las cesiones de I 303 y 1335 de partes del término isleño parecen apuntar a que si bien no demasiado numerosas estas explotaciones eminentemente agropecuarias debieron estar diseminadas tanto en la propia isla como en la zona continental del alfoz. La pesca debió constituir otro recurso interesante para estos primeros repobladores de La Puente, pues a las innegables condiciones naturales que motivaron su explotación desde la Antigüedad (BERNAL ET ALII, 2003), hay que unir la documentación de restos de utensilios de pesca y pesas de red de los ss. XIV-XV en el castillo isleño (SÁEZ, TORREMOCHA y SÁEZ, 2004). El castillo presumiblemente preexistente sería quizá reformado o rehabilitado como centro de poder de La Puente, como sede de su concejo y quizá de la parroquia asociada al poblado. Se trata, a pesar del despoblamiento de la etapa central del s. XIII, de un momento de cierta continuidad, seguramente con un bajo número de repobladores en consonancia con otros puntos de la bahía, formando un núcleo que no terminaría de consolidarse hasta la transición al s. XIV con un amplio alfoz a caballo entre la isla gaditana y la campiña continental anexa explotado a través de algunas alquerías 0 aldeas.

\section{La desintegración territorial del término de La Puente: Chiclana (1303) y Rayhana (1335)}

Sin embargo, el territorio de La Puente (y por ende el de Cádiz), iba a ser recortado sucesivamente a partir de los primeros compases del s. XIV a favor de nuevos intereses señoriales. En 1303 Chiclana era desgajada del término isleño a favor de Alonso Pérez de Guzmán con la finalidad de que éste retomase el proceso repoblador en la aldea y la dotase de fortificación, al igual que había hecho apenas un lustro antes con la aldea de Conil (CASTILLO, VELÁZQUEZ-GAZTELU y GONZÁLEZ, 1982; BOHÓQUEZ, 1996). Los intereses de la casa de los Guzmanes por Chiclana giraban proba- blemente entorno no sólo a integrar un nuevo fértil término agrícola a sus dominios o a su cercanía a la bahía y a una vía fluvial clave como el caño de Sancti Petri, sino que entraban dentro de su línea de expansión por la costa atlántica e relación a la explotación almadrabera (LADERO, 1993), negocio que en el entorno de Conil y Zahara les proporcionaba pingües beneficios. Su posición privilegiada en la explotación de esta pesca estacional a partir del privilegio dado por Sancho IV a raíz de la defensa de Tarifa una década antes sin duda contribuyó a fijar la atención sobre Chiclana, que poseía costas adecuadas para estas almadrabas de vista y asimismo contaba con abundantes y cercanas salinas que surtieran las chancas para elaborar la salazón de atún. La cesión fugaz entre 1335 y I 344 de la alquería de Rayhana a Gonzalo Díaz de Sevilla responde a otros intereses netamente diferenciados, quizá relacionados con las ansias expansivas del alfoz jerezano durante su segundo periodo fundacional (MARTíN, 2003), frente a las cuales pueden entreverse gracias al documento de reversión de la propiedad los intereses de Cádiz en conservar el dominio sobre La Puente.

Poco sabemos en esta fase de la evolución del Logar de la Puente además de la continuidad de la actividad marítima-mercantil en el caño, mencionándose por vez primera la fortaleza y la capilla de Santa María. Es probable que se trate de un periodo de cierta consolidación de los procesos socio-económicos iniciados en la fase repobladora anterior, con la continuidad de las actividades pesqueras, salineras y agropecuarias.

\section{Los devastadores efectos del ataque luso de 1369. La desaparición del Concejo}

Las alusiones a los destrozos causados en la fortaleza y sus términos contenidas en los documentos de cesión a los Suazo y las pruebas arqueológicas documentadas en las excavaciones del Castillo de la Puente permiten poco margen de duda respecto a la entidad de la destrucción del ataque portugués de 1369 70 . Sus consecuencias conllevarían la ruina par- 
cial del castillo, pero sobre todo el incendio y abandono casi total del poblado, el puente, las alquerías, las explotaciones agrícolas y salineras, etc... perdiéndose los archivos, y en general la entidad que la zona había tenido como concejo autónomo dependiente del gaditano, siendo el retroceso poblacional probablemente casi total. Esta pérdida de la identidad como ámbito poblacional generará la imagen de lugar de expansión rural de Cádiz de los siglos sucesivos hasta el impulso urbano del s. XVIII. La cesión a la familia Vera del señorío isleño no debió suponer cambios sustanciales, dejando al margen la recuperación de la habitabilidad del propio castillo, pues las propiedades y el puente continuaban arruinados aún a inicios del s. XV. Sin embargo, ciertos indicios señalan que el retroceso y abandono debido al ataque de 1369 no significó una ruptura radical con las realidades económicas preexistentes, pues algunos documentos señalan la transmisión de heredades dedicadas al cultivo de la vid durante la segunda mitad del XIV hasta después de la cesión a Juan Sánchez de Suazo (CRISTELLY, I89I: 68; FRANCO SILVA, 1995: 37, nota 4). Finalmente cabe señalar de esta convulsa etapa cómo las dificultades poblacionales y jurisdiccionales seguramente motivaron la pérdida del área continental del término aún perteneciente a La Puente, situados en la disputada área del caño Zurraque y el actual núcleo urbano de Puerto Real, quizá anexionados entonces al alfoz jerezano (SANCHO DE SOPRANIS, 1955; MARTíN, 2003: I31), problemas que no se solucionarían con la usurpación gaditana de |48| o la fundación de Puerto Real en | 483 sino que aún deberían ser resueltos por la corona en I5I8 (MARTíN, 2003: I53).

\section{La recuperación bajo el régimen señorial. La Isla en el S. XV}

La donación del señorío de La Puente a los Suazo sí supuso una etapa de reactivación del término y de reconstrucción en general tanto de la fortaleza como del puente, así como la reanudación a cierto nivel de las explotaciones agrícolas y salineras-pesqueras. La reconstrucción del puente, al margen de la barca que ya se encontraba en funcionamiento y suponía una de las principales rentas del término, fue la principal dedicación del primero de los Suazo sin duda con un fin económico claro, el cobro de los derechos de paso entre la isla gaditana y el continente. A este respecto, debemos señalar cómo desde mediados de la centuria tenemos constancia de la instalación en la desembocadura meridional del caño de una barca en dirección a Chiclana (BOHÓRQUEZ, 1996: 106 y 150) y en el mismo periodo en unión a la usurpación gaditana de tierras en la zona del intento de instalación de otro barcaje entre Matagorda y Puntales (MARTíN, 2003), a pesar de los privilegios obtenidos para el paso por los gaditanos desde la década de los sesenta. Asimismo, los Suazo se ocuparon de reconstruir el castillo, reconvertido en casa fuerte señorial y residencia y lugar de enterramiento familiar, en paralelo a una recuperación de la implantación de explotaciones dedicadas fundamentalmente a la plantación de viñedos, fenómeno bien conocido a partir del s. XVI (FRANCO SILVA, 1995). Las salinas, especialmente las situadas en la ribera del caño de Sancti Petri, explotadas como antes señalábamos desde la fase inicial de la repoblación, quizá reactivaron su actividad en un momento pleno de esta centuria, pero sobre todo a partir de las últimas décadas en consonancia con los datos de otras localidades del entorno (FRANCO SILVA, 1995: 586I; Ibid. 1997; MARTíN, 2003: 89-10I). El interés de Cádiz por reintegrar el resto de la isla a su término y los propios intereses particulares de Rodrigo Ponce de León en el mismo sentido acabaron con el dominio de los Suazo gracias a la permuta de |490-1492, si bien este cambio de señores no significó parón alguno en el proceso de recuperación socio-económica experimentado desde los inicios del $\mathrm{XV}$, tendencia que generaría la imagen bien reflejada en la obra de Horozco (1598) y que se convertiría en seña de identidad de la isla hasta las reformas borbónicas de mediados del XVIII (FRANCO SILVA, 1995). 


\section{BIBLIOGRAFÍA}

ABELLÁN, J. (1996): El Cádiz islámico a través de sus textos. Cádiz.

ABELLÁN, J. (2002): "Urbanismo religioso en la cora de Medina Sidonia", Actas del II Congreso Internacional La ciudad en al-Andalus y el Magreb (Algeciras, 1999), Granada, pp. $|2|-\mid 38$.

ABELLÁN, J., (2004): Poblamiento y administración provincial en al-Andalus. La cora de Sidonia, Ed. Sarriá, Málaga.

ABELLÁN, J. (e. p.): "El final de al-Andalus en tierras gaditanas (siglo XIII): poblamiento", El Castillo de San Romualdo: un monumento en la historia. XVIII Encuentros de Historia y Arqueología (San Fernando, 2002).

ALONSO, C., GRACIA, F. J., y MENANTEAU, L., (2003): "Las salinas de la Bahía de Cádiz durante la Antigüedad: visión geoarqueológica de un problema histórico", Spal, 12, Universidad de Sevilla, pp. 317-332.

BERNAL, D., SÁEZ, A., SÁEZ, A. M., DÍAZ, J. J., LORENZO, L., y TOLEDO, F., (2003): Carta arqueológica municipal de San Fernando (Cádiz), Junta de Andalucía, Sevilla.

BOHÓRQUEZ, D., (1996): Chiclana de la Frontera. Geografia, Historia, Urbanismo y Arte, Cádiz.

BUSTAMENTE, J., (1998): "Topografía de las aldeas de Vejer según los repartimientos", en Ramos et alii, (Eds.) Excavaciones arqueológicas en La Mesa (Chiclana de la Frontera, Cádiz). Campaña de 1998. Aproximación al estudio del proceso histórico de su ocupación, Serie Monográfica. Arqueología en Chiclana de la Frontera, I, Ayto. de Chiclana y Fundación Viprén, Chiclana.

CASTILLO, A.; VELÁZQUEZ-GAZTELU, F., y GONZÁLEZ DE CALDAS, M. C., (1982): Chiclana de la Frontera, Colección «Los Pueblos de la Provincia de Cádiz», Diputación Provincial, Cádiz.

CAVILLA, F. (2002a): "El Cádiz medieval", Cádiz al fin del milenio. Cinco años de Arqueología en la ciudad (19952000). Catálogo de la Exposición (Cádiz, 2002), Sanlúcar de Barrameda, pp. 59-68.

CAVILLA, F. (2002b): "Anafes musulmanes de doble cámara de Sancti-Petri (San Fernando, Cádiz)", Estudios sobre Patrimonio, Cultura y Ciencia Medievales, III, Cádiz, pp. 37-67.

CAVILLA, F., (2003): "San Fernando en época medieval islámica", en D. Bernal et alii, (Eds.) Carta arqueológica municipal de San Fernando (Cádiz), Junta de Andalucía, Sevilla (en prensa), pp. 329-346.

CAVILLA, F. (e.p.): "Panorama de la Arqueología musulmana en San Fernando (Cádiz)", El Castillo de San Romualdo: un monumento en la Historia. XVIII Encuentros de Historia y Arqueología (San Fernando, 2002).

CLAVIJO Y CLAVIJO, S. (196I): La ciudad de San Fernando. Historia y espíritu, Ayto. de San Fernando, 2 vol., Cádiz.
CRISTELLY LABORDE, J. ( 89 |): Ligeros apuntes históricos y colección de citas, documentos y datos estadísticos de la ciudad de San Fernando, San Fernando.

CONCEPCIÓN, Gerónimo de la (1690): Emporio de el Orbe, Cádiz llustrada. Ámsterdam.

FERNÁNDEZ, R., GARCÍA, M. E., y SÁNCHEZ, M., (2003): "Una primera aproximación al poblamiento islámico en la campiña litoral gaditana (Chiclana de la Frontera, Cádiz). Campaña de 2000", Anuario Arqueológico de Andalucía/2000, II, Sevilla, pp. 17-23.

FIERRO CUBIELLA, J. A., (|99|): El castillo del Lugar de la Puente en San Fernando (Cádiz), Cádiz.

FRANCO SILVA, A., (1995): La Isla de León en la Baja Edad Media, Excmo. Ayuntamiento de S. Fernando, Fundación Municipal de Cultura, Cádiz.

FRANCO SILVA, A., (1997): "Las salinas de la Isla de León a fines de la Edad Media", La sal: del gusto alimentario al arrendamiento de salinas (Malpica, A., y González, J. A., Eds.), Diputación Provincial de Granada, Centro de Investigaciones Etnológicas Ángel Ganivet, Granada, pp. 143-167.

GALLARDO, M., GARCÍA, C., ALONSO, C., y MARTÍ, J. (1995): "Carta arqueológica subacuática de la Bahía de Cádiz", Cuadernos de Arqueología Marítima, 3, Cartagena, pp. 105- 122.

GALLARDO, M., y MARTÍ, J. (1998): "Prospección arqueológica de emergencia en el Caño de Sancti Petri", AAA /1994, III, Puerto Real, pp. 4I-46.

GALLARDO, M., MARTÍ, J., ALONSO, C., y GARCÍA, C. (1998): "Prospecciones arqueológicas subacuáticas en Sancti Petri. Proyecto General de investigación de la Bahía de Cádiz, Carta Arqueológica Subacuática", AAA //994, II, Puerto Real, pp. 44-48.

GONZÁLEZ JIMÉNEZ, M., (1982): "El Puerto de Santa María en tiempos de Alfonso X (1264-1284)", Gades, 9 , Cádiz, pp. 209-242.

GONZÁLEZ JIMÉNEZ, M., (1983): "La obra repobladora de Alfonso X en las tierras de Cádiz", Cádiz en el siglo XIII, Actas de las Jornadas Conmemorativas del VII Centenario de la muerte de Alfonso X el Sabio, Cádiz, pp. 7-20.

GONZÁLEZ JIMÉNEZ, M., (1999): "Una «noble Çibdat e bona»: fundación y poblamiento de El Gran Puerto de Santa María", Alcanate, I (1998-99), Cátedra Alfonso X el Sabio, Cádiz, pp. 19-28.

GONZÁLEZ JIMÉNEZ, M., (Ed.) (2002): Repartimiento de El Puerto de Santa María, Sevilla-El Puerto de Santa María.

HOROZCO, A., ( 1598): Historia de la Ciudad de Cádiz., en A. Morgado (Ed.) Historia de Cádiz, Colección Fuentes para la historia de Cádiz y su provincia, 4, Cádiz (200I).

LADERO, M. A., (1993): "Las almadrabas de Andalucía (siglos XIII-XVI)", Boletín de la Real Academia de la Historia, CXC, cuaderno III, Madrid, pp. 345-354. 
LADERO, M. A., y GONZÁLEZ, M., (1977): "La población en la frontera de Gibraltar y el repartimiento de Vejer (siglos XIII y XIV)", HID, 4, Sevilla, pp. 199-3I7.

LÓPEZ GARRIDO, J. L., (1992): El Privilegio Rodado de los Reyes Católicos a Cádiz en 1493, Cádiz.

MARTÍN GUTIÉRREZ, E., (2003): La identidad rural de Jerez de la Frontera. Territorio y poblamiento durante la Baja Edad Media, Servicio Publicaciones UCA, Cádiz.

MARTíN GUTIÉRREZ, E., (2004): La organización del paisaje rural durante la Baja Edad Media. El ejemplo de Jerez de la Frontera, Universidades de Sevilla y Cádiz, Madrid.

MÓSIG PÉREZ, F., (2004): Informe histórico sobre el Castillo de San Romualdo (Informe depositado en el Museo Histórico Municipal de San Fernando, junio-septiembre de 2004).

PAVÓN, B. (1996): "El arco del Pópulo. En torno al Cádiz musulmán", Al-Qantāra, XVII, fasc. I, Madrid, pp. |7|-20I.

PAVÓN, B. (1999): Tratado de arquitectura hispanomusulmana II. Ciudades y fortalezas. Madrid.

RAMOS, J., MONTAÑÉS, M., PÉREZ, M., CASTAÑEDA, V., HERRERO, N., GARCÍA, M. E., CÁCERES, I., (Eds.) (1998): Excavaciones arqueológicas en La Mesa (Chiclana de la Frontera, Cádiz). Campaña de 1998. Aproximación al estudio del proceso histórico de su ocupación, Serie Monográfica. Arqueología en Chiclana de la Frontera, I, Ayto. de Chiclana y Fundación Viprén, Chiclana.

RUIZ GIL, J. A., (1994): "Los orígenes de San Fernando: una aportación desde el Castillo de San Romualdo", Actas de los X Encuentros de Historia y Arqueología, San Fernando, pp. 87-95.

RUIZ, D. y PÉREZ, C., (1995): El poblado fenicio del Castillo de Doña Blanca (El Puerto de Santa María, Cádiz) Colección de Temas Portuenses, 5, El Puerto de Santa María.

SÁEZ ROMERO, A. M., (e.p.): "El Castillo de la Puente (San Fernando, Cádiz): una fortaleza olvidada", Castillos de España, AEAC, Madrid.

SÁEZ ESPLIGARES, A., TORREMOCHA, A., y SÁEZ ROMERO, A. M., (2004): "Informe de las actividades arqueológicas desarrolladas en el Castillo de San Romualdo (San Fernando, Cádiz). Campañas de 2000 y 200।", Anuario Arqueológico de Andalucía/200 I, III, Sevilla, pp. I I I120.
SÁEZ ESPLIGARES, A., TORREMOCHA, A., y SÁEZ ROMERO, A. M., (e.p. a): "Avance de las nuevas actuaciones arqueológicas acometidas en el Castillo de San Romualdo (San Fernando, Cádiz). Campaña de 2003", Anuario Arqueológico de Andalucía/2003, Sevilla.

SÁEZ ESPLIGARES, A., TORREMOCHA, A., y SÁEZ ROMERO, A. M., (e.p. b): "Nuevas perspectivas arquitectónicas en el Castillo de San Romualdo (San Fernando, Cádiz): el foso defensivo", Congreso Internacional de Patrimonio Histórico «Criterios de restauración y proyectos innovadores en fortificaciones costeras»), Proyecto Almenasur, Gerencia Municipal de Urbanismo de San Fernando, San Fernando (Noviembre 2004)

SÁEZ ROMERO, A. M., MONTERO, R., MONTERO, A. I., y DÍAZ, J. J., (e.p.): "Nuevos datos para el estudio del trazado de la Vía Augusta a su paso por San Fernando (Cádiz): aportaciones desde el Castillo de San Romualdo y su entorno", XVIII Encuentros de Historia y Arqueología de San Fernando, San Fernando 2002.

SÁEZ ROMERO, A. M., MONTERO, R., MONTERO, A. I., SÁEZ, A., y DÍAZ, J. J., (2005): "Anotaciones al recorrido de las vías Augusta y Heraclea a su paso por San Fernando (Cádiz). Novedades arqueológicas y paleogeográficas", Antiquitas, 16, Priego de Córdoba, pp. 105-119.

SÁNCHEZ HERRERO, J., ( 1986): Cádiz. La ciudad medieval y cristiana (1 260-1525), Córdoba.

SÁNCHEZ SAUS, R., (1996): Linajes medievales de Jerez de la Frontera, 2 vols., Sevilla.

SÁNCHEZ SAUS, R., (1997): "La singularidad de Jerez a la luz del proceso de formación de su nobleza (siglos XIII al XV)", Trivium. Anuario de Estudios Humanísticos, 9, pp. 179-194.

TORRES BALBÁS, L., (1950): "El Castillo del Lugar de la Puente en la Isla de Cádiz", Al-Andalus, XV, Madrid, pp. 202-2। 4.

VALDEÓN BARUQUE, J., (1966): Enrique II de Castilla. La guerra civil y la consolidación del régimen (I 366- | 37 |). Valladolid.

ZURITA, D. M., (1947): "La Isla de Cádiz en el siglo XV", Hispania, XXVII, pp. 222-255. 


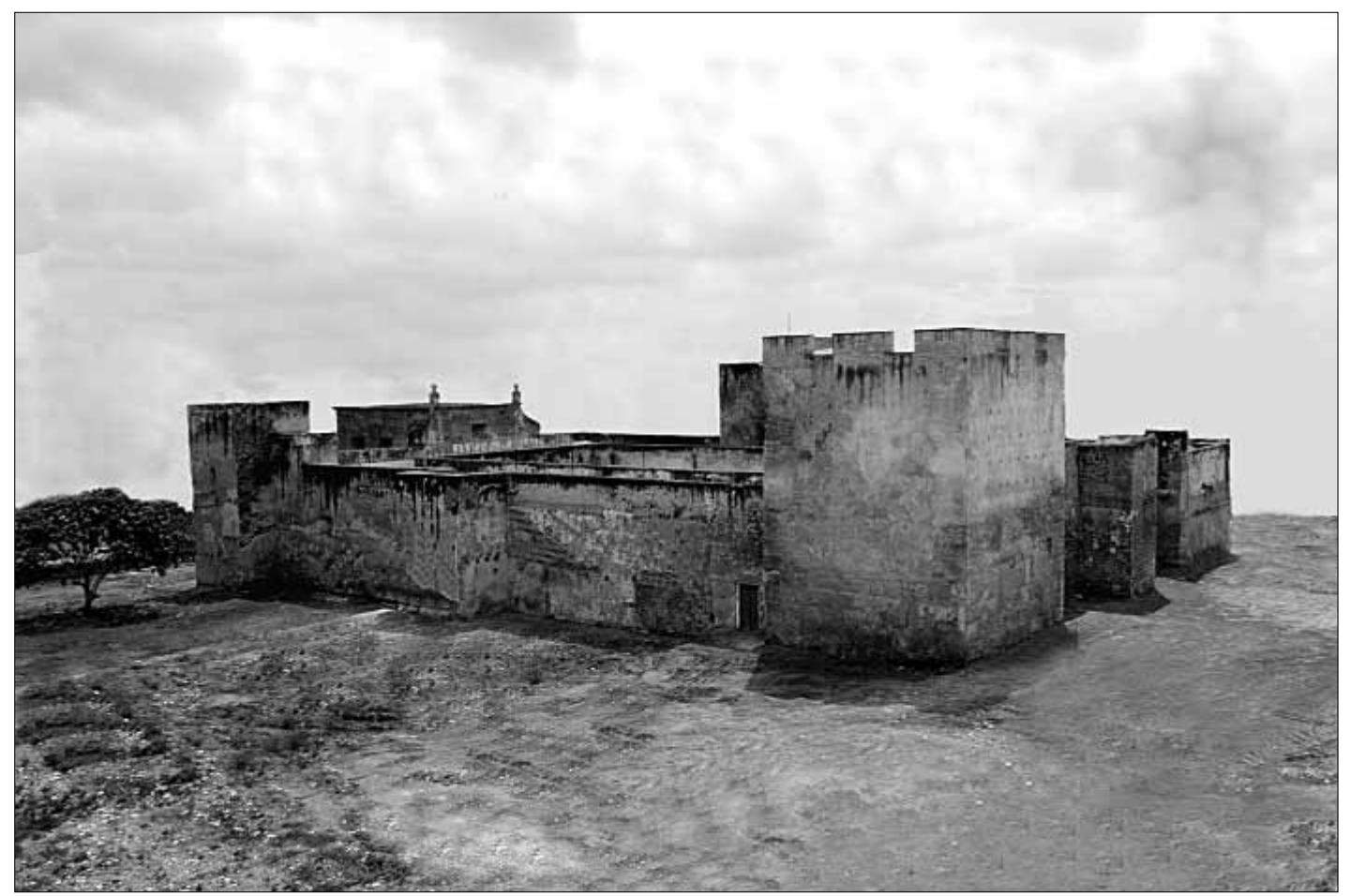

Lam. I. Aspecto actual del Castillo de La Puente o de San Romualdo visto desde el norte, principal fortaleza medieval conservada en el ámbito insular gaditano (imagen cedida por E. Rioja)

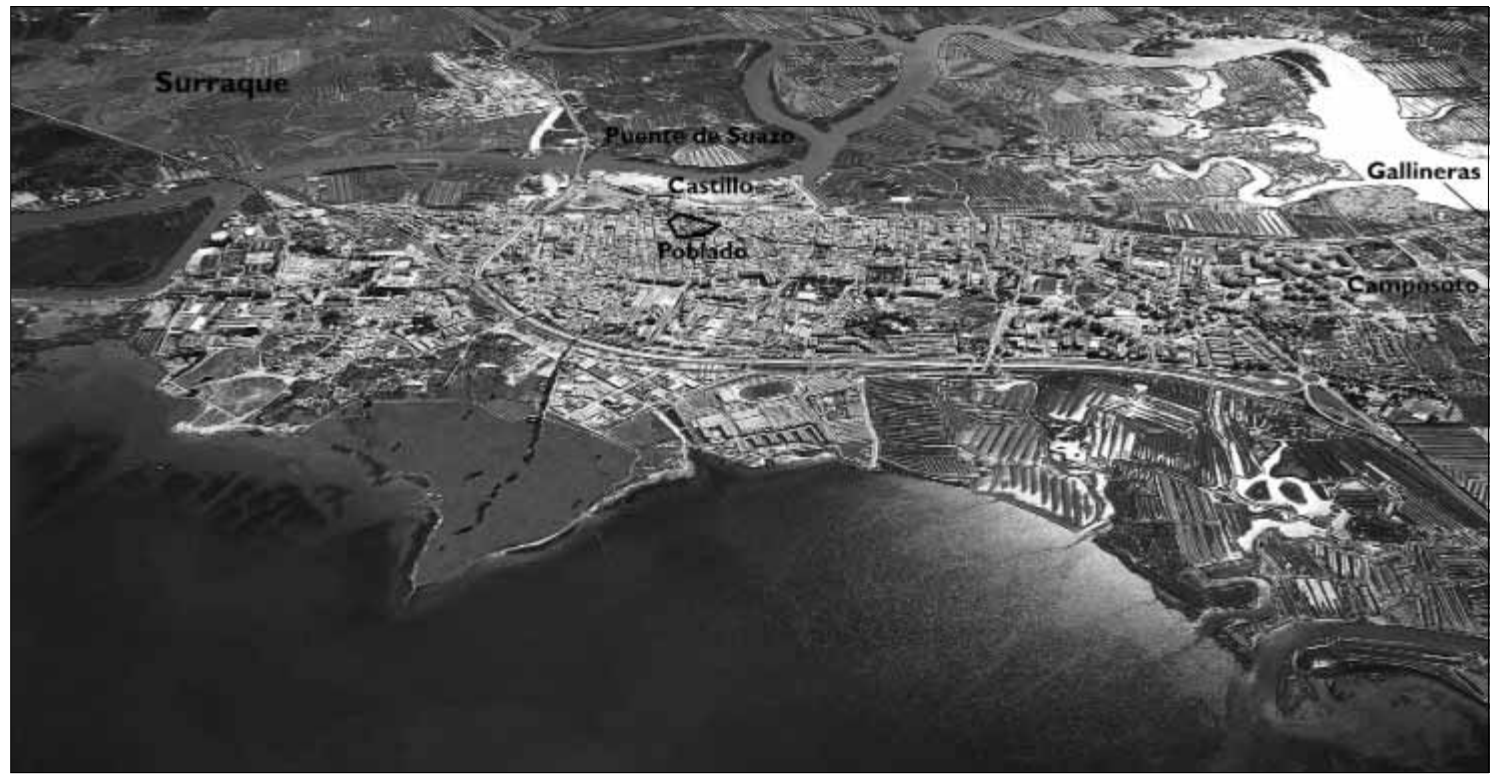

Lam. 2. Vista aérea de la zona central de San Fernando, con indicación de los hitos histórico-arqueológicos más destacados en relación al poblamiento medieval (imagen extraída de www.laisladelsur.com) 


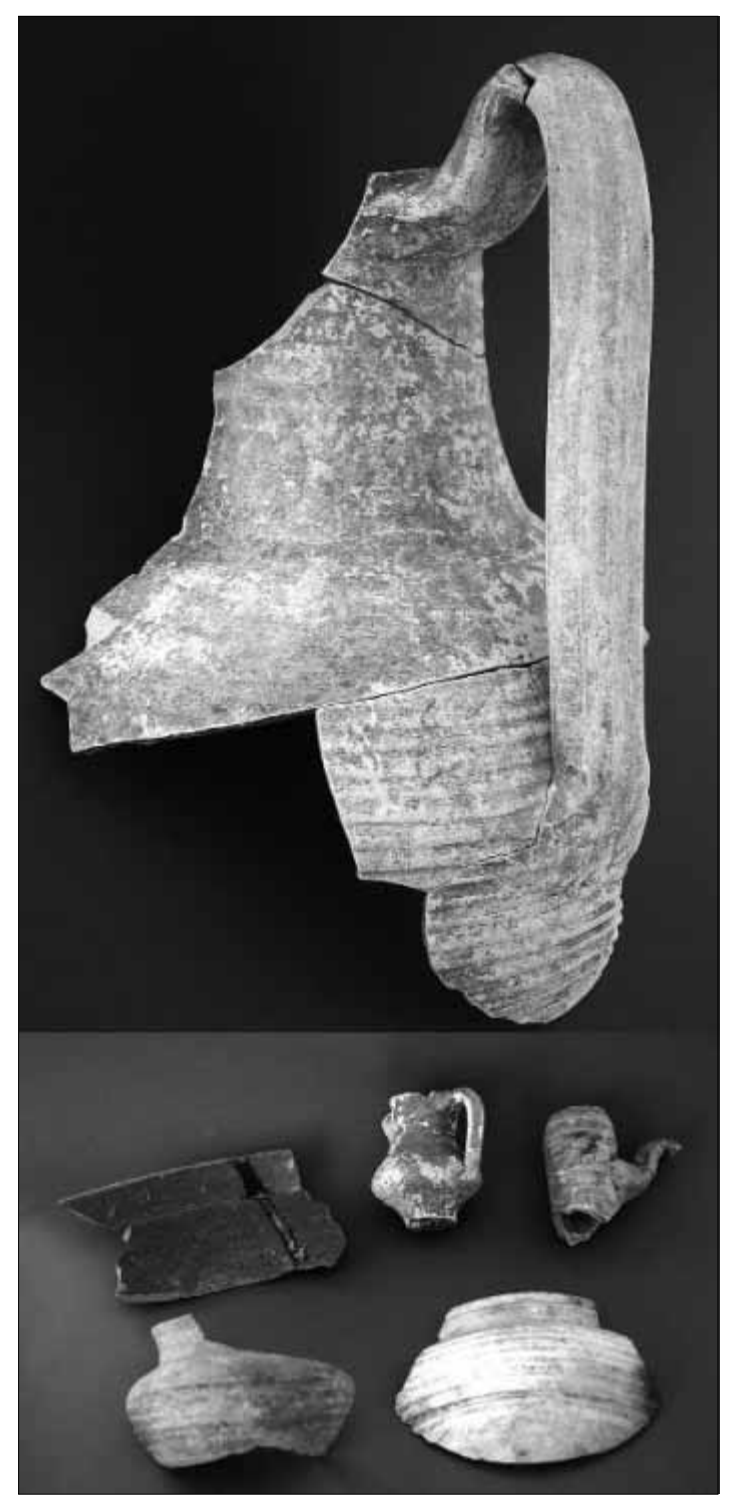

Lam. 3. Materiales cerámicos islámicos recupera-

dos en un silo agrícola del yacimiento

de Campo del Gayro en la intervención de 1998

Lam. 4. Vista aérea de parte del área continental del término de La Puente, con indicación de las salinas del Zurraque y la zona presumiblemente ocupada por la alquería de Rayhana (imagen extraída de www.laisladelsur.com).

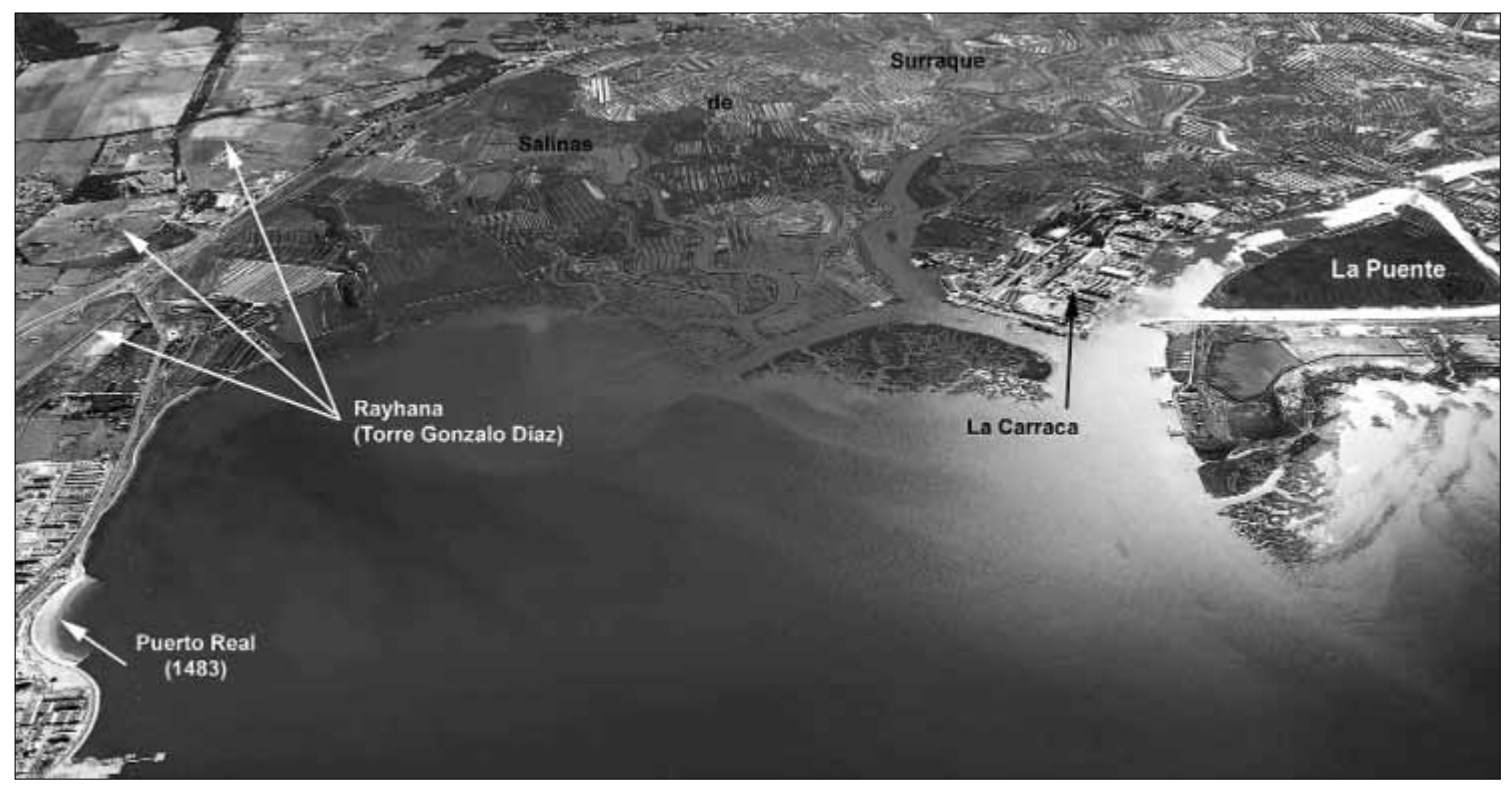




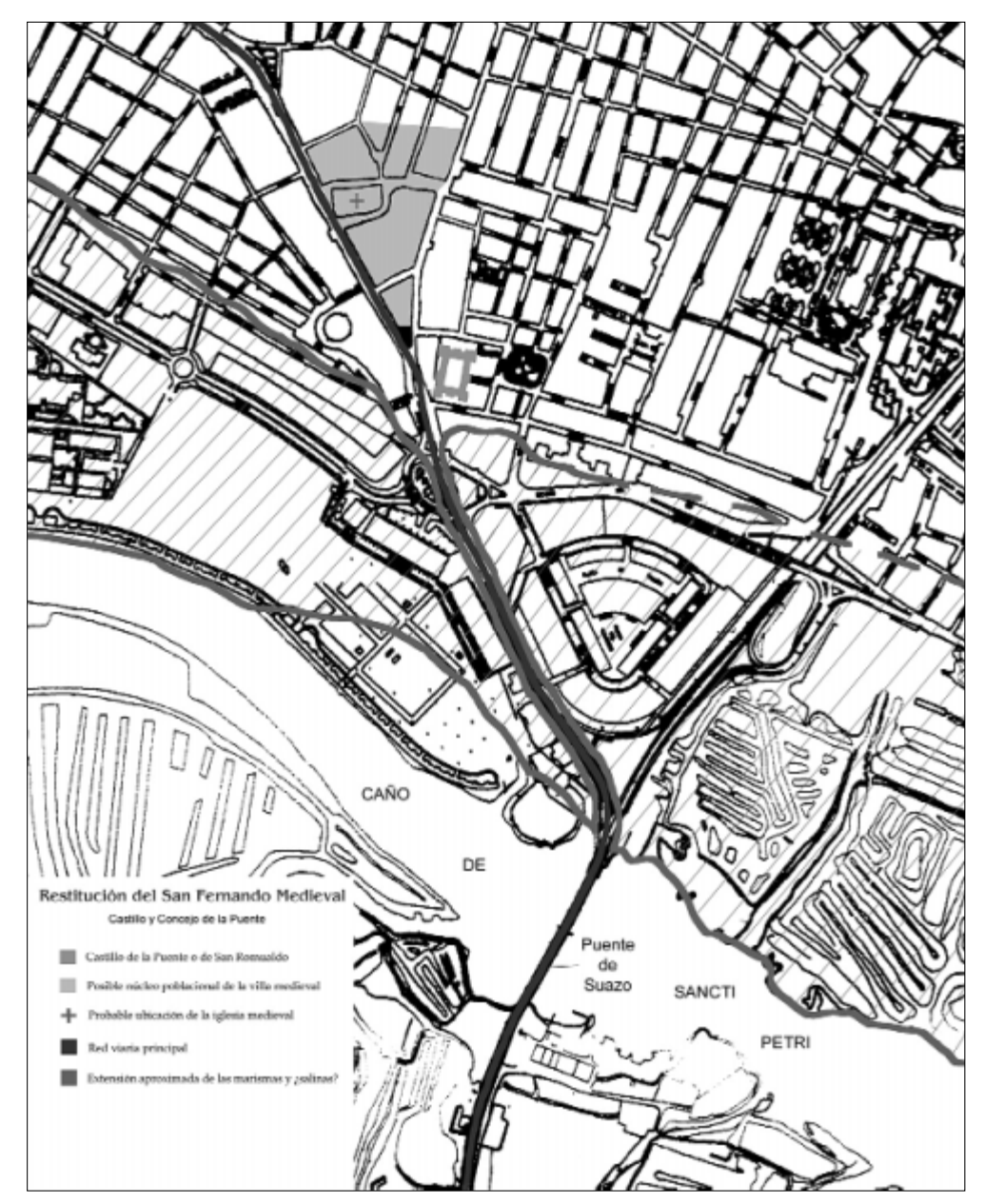

Lam. 5. Hipótesis acerca de la ubicación del poblado bajomedieval de La Puente (ss. XIII-XIV), señalando la posible situación de edificios religiosos y la paleotopografía del entorno en base a la evidencia arqueológica

Lam. 6. Sondeos arqueológicos acometidos en 2000-2003 y posible trazado de las áreas oeste y sur del foso (según SÁEZ, TORREMOCHA y SÁEZ, e.p.).

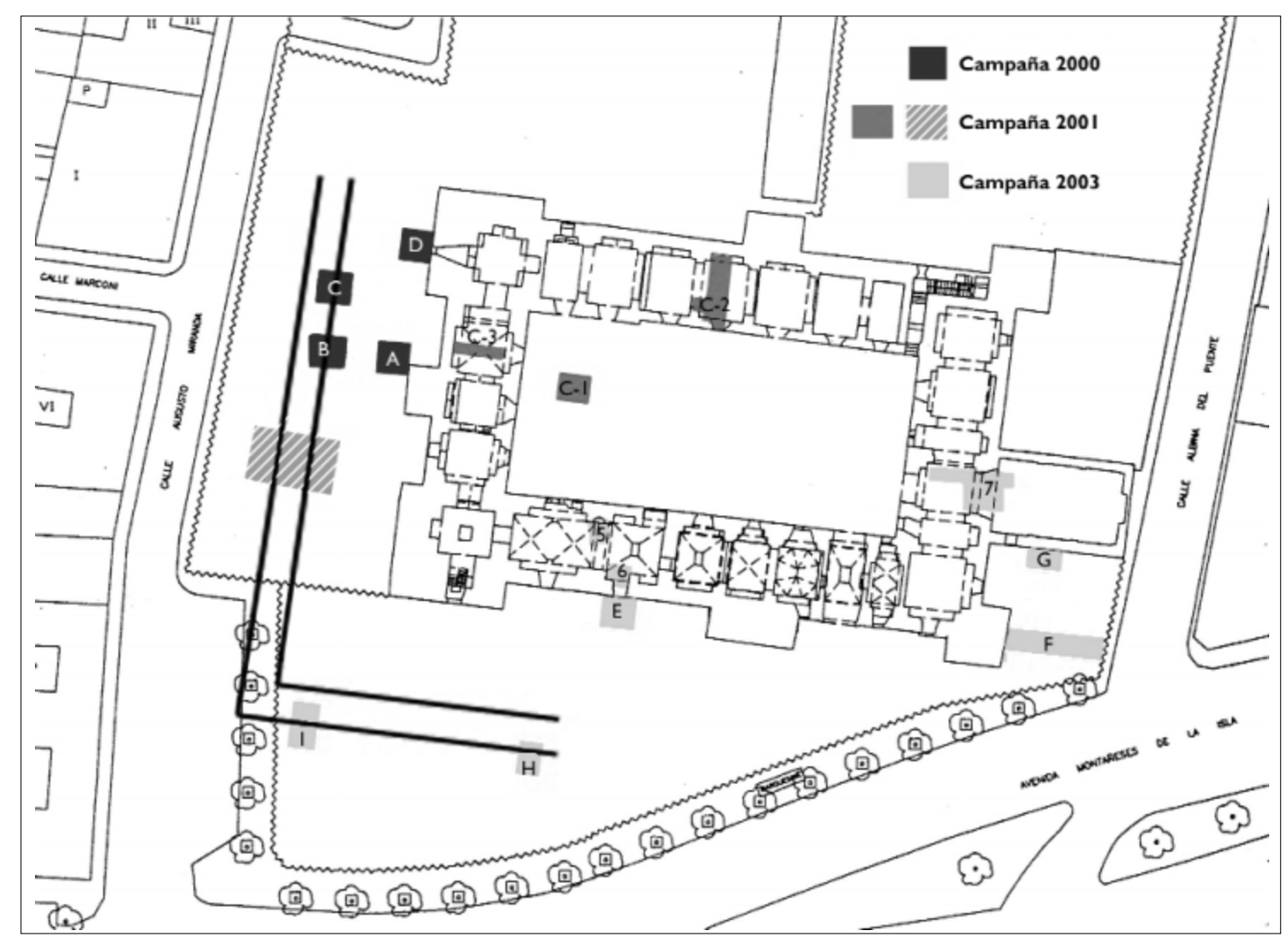




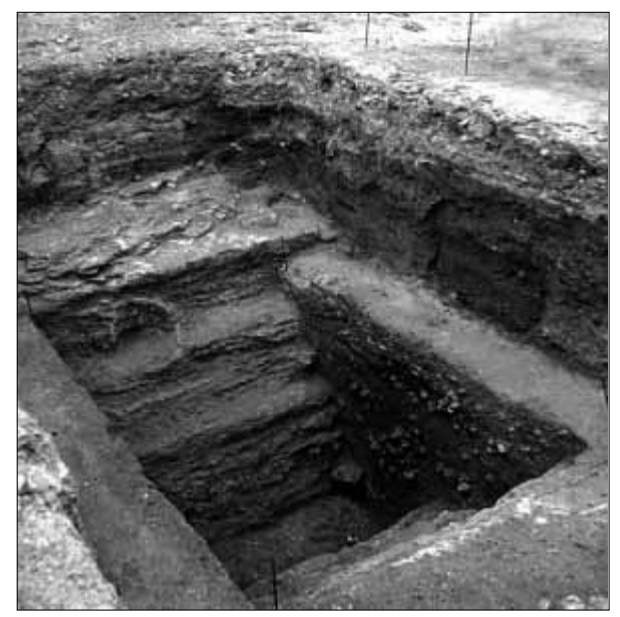

Lam. 7. Sección de la cava del

flanco oeste de la fortaleza

exhumada en 2001

Lam. 8a. Cerámicas bajomedievales valencianas del s. XIV procedentes del foso del Castillo de La Puente (según SÁEZ, TORREMOCHA y SÁEZ, e.p.)

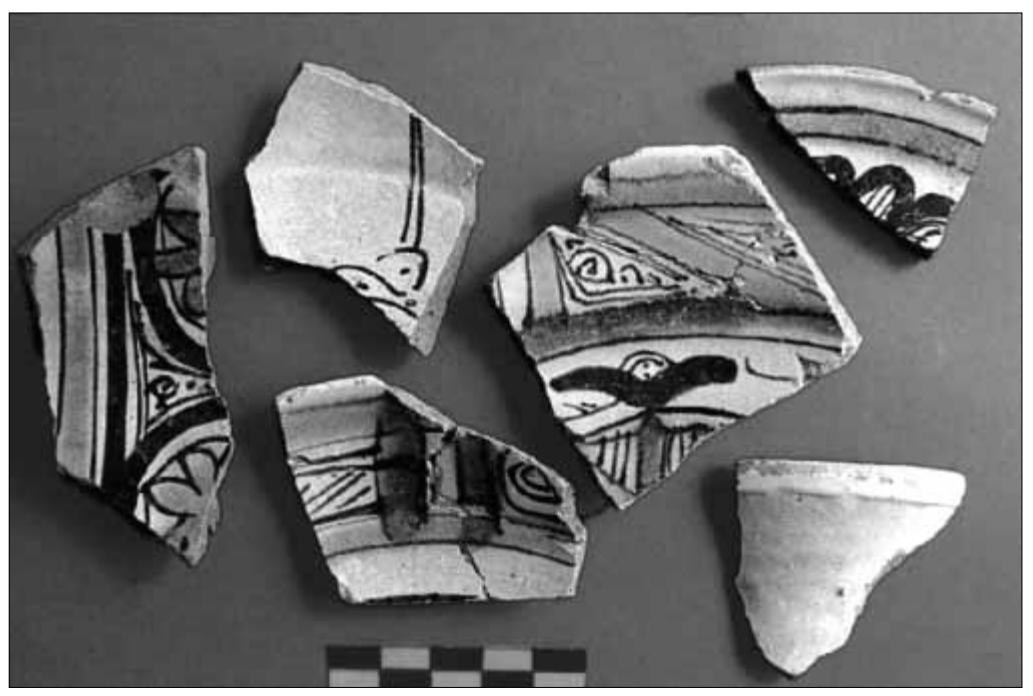

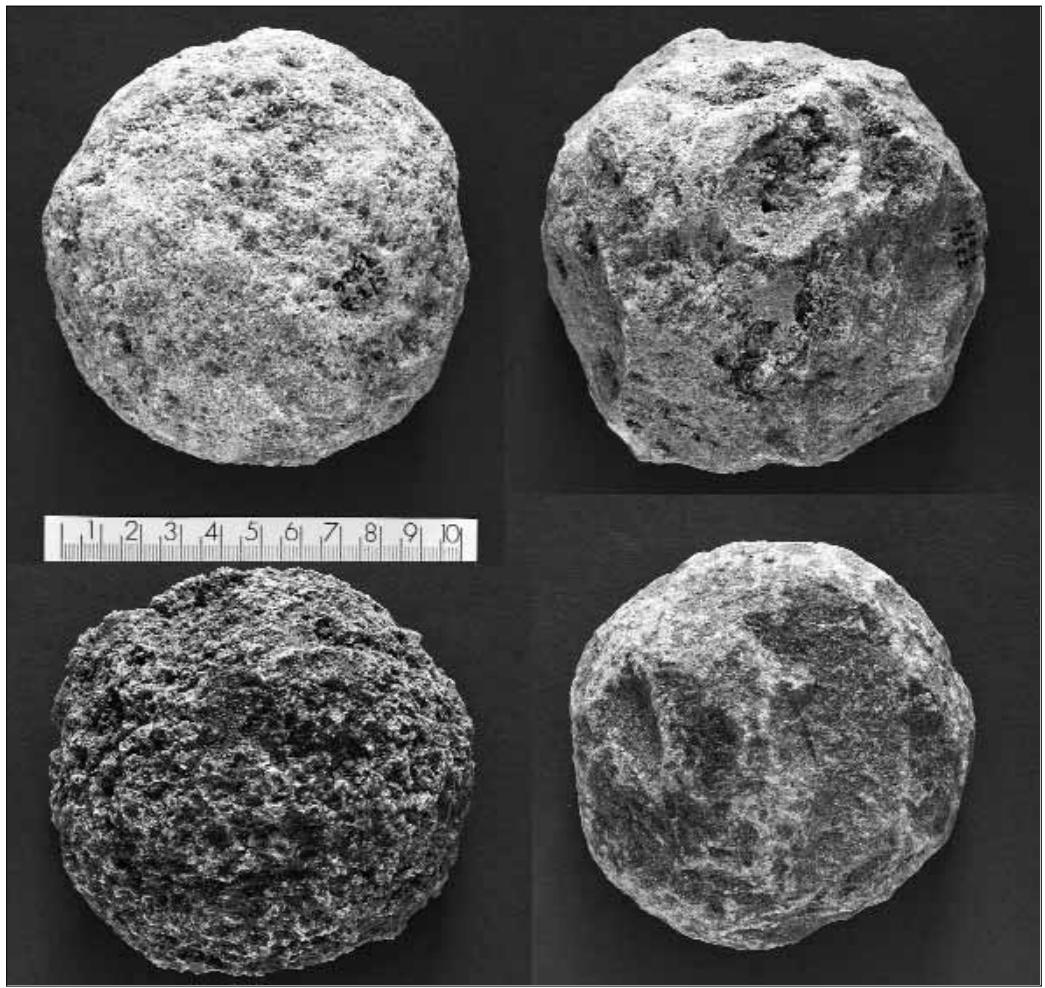

Lam. 8b. Fragmentos de bolaños de tamaño medio documentados en niveles medievales del relleno de la zona oeste de la cava del Castillo de la Puente 
Lam. 9. Puntas de flechalballesta y nuez de ballesta recuperadas en el relleno del foso del castillo

Lam. I0. Ensayo de reconstrucción del término bajomedieval de La Puente, con indicación de las áreas continentales perdidas durante el s. XIV, así como el poblamiento de los términos circundantes (elaboración propia a partir de BUSTAMANTE, 1998; GONZÁLEZ, 2002; y MARTíN, 2004)
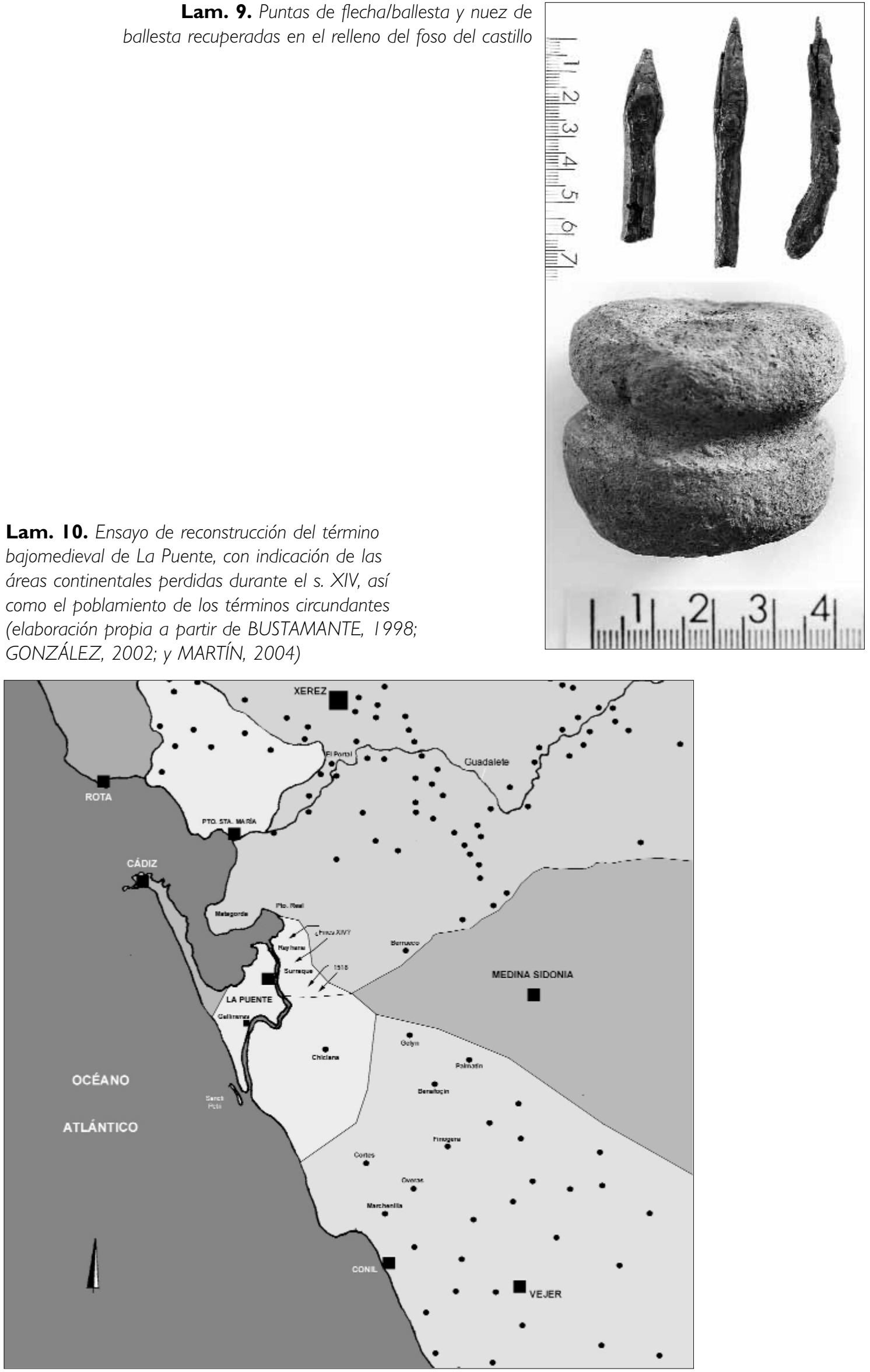